\title{
əThe Opposing Effects of Reforestation and Afforestation on the Diurnal Temperature Cycle at the Surface and in the Lowest Atmospheric Model Level in the European Summer
}

\author{
M. Breil, ${ }^{\mathrm{a}}$ D. Rechid, ${ }^{\mathrm{b}}$ E. L. Davin, ${ }^{\mathrm{c}}$ N. De Noblet-Ducoudré, ${ }^{\mathrm{d}}$ E. Katragkou, ${ }^{\mathrm{e}}$ R. M. CARdoso, ${ }^{\mathrm{f}}$ \\ P. Hoffmann, ${ }^{\text {b }}$ L. L. Jach, ${ }^{\mathrm{g}}$ P. M. M. SoAres, ${ }^{\mathrm{f}}$ G. Sofiadis, ${ }^{\mathrm{e}}$ S. Strada, ${ }^{\mathrm{h}}$ G. Strandberg, ${ }^{\mathrm{i}}$ M. H. Tölle, ${ }^{\mathrm{j}}$ And \\ K. WARRACH-SAGI ${ }^{\mathrm{g}}$ \\ ${ }^{\mathrm{a}}$ Institute for Meteorology and Climate Research, Karlsruhe Institute of Technology, Karlsruhe, Germany; ${ }^{\mathrm{b}}$ Climate Service Center \\ Germany, Helmholtz-Zentrum Geesthacht, Hamburg, Germany; ${ }^{c}$ Department of Environmental Systems Science, ETH Zurich, \\ Zurich, Switzerland; ${ }^{\mathrm{d}}$ Laboratoire des Sciences du Climat et de l'Environnement, Gif-sur-Yvette, France; ${ }^{\mathrm{e}}$ Department of \\ Meteorology and Climatology, School of Geology, Aristotle University of Thessaloniki, Thessaloniki, Greece; ${ }^{\mathrm{f}}$ Instituto Dom Luiz, \\ Faculdade de Ciências, Universidade de Lisboa, Lisboa, Portugal; ${ }^{\mathrm{g}}$ Institute of Physics and Meteorology, University of Hohenheim, \\ Stuttgart, Germany; ${ }^{\mathrm{h}}$ International Center for Theoretical Physics, Earth System Physics Section, Trieste, Italy; ${ }^{\mathrm{i}}$ Rossby Centre, \\ Swedish Meteorological and Hydrological Institute, Norrköping, Sweden, ${ }^{j}$ Department of Geography, Climatology, Climate \\ Dynamics and Climate Change, Justus-Liebig University Giessen, Giessen, Germany
}

(Manuscript received 16 August 2019, in final form 28 May 2020)

\begin{abstract}
The biophysical effects of reforestation and afforestation (herein jointly called re/afforestation) on the diurnal temperature cycle in European summer are investigated by analyzing a regional climate model (RCM) ensemble, established within the Land Use and Climate Across Scales Flagship Pilot Study (LUCAS FPS). With this RCM ensemble, two idealized experiments are performed for Europe, one with a continent with maximized forest cover, and one in which all forests are turned into grassland. First, an in-depth analysis of one ensemble member ("CCLM-VEG3D") is carried out, to reveal the complex process chain caused by such land use changes (LUCs). From these findings, the whole ensemble is analyzed and principal biophysical effects of re/afforestation are derived. Results show that the diurnal temperature range is reduced at the surface (top of the vegetation) with re/afforestation. Most RCMs simulate colder surface temperatures $T_{\text {surf }}$ during the day and warmer $T_{\text {surf }}$ during the night. Thus, for the first time, the principal temperature interrelations found in observation-based studies in the midlatitudes could be reproduced within a model intercomparison study. On the contrary, the diurnal temperature range in the lowest atmospheric model level $\left(T_{\text {air }}\right)$ is increased with re/afforestation. This opposing temperature response is mainly caused by the higher surface roughness of forest, enhancing the turbulent heat exchange. Furthermore, these opposing temperature responses demonstrate that the use of the diagnostic 2-m temperature (weighted interpolation between $T_{\text {surf }}$ and $T_{\text {air }}$ ) has a limited potential to assess the effects of re/afforestation. Thus, studies about the biophysical impacts of LUCs should investigate the whole near-surface temperature profile.
\end{abstract}

KEYWORDS: Europe; Vegetation-atmosphere interactions; Surface temperature; Land surface model; Regional models; Land use

\section{Introduction}

Land use change (LUC) modifies the biophysical characteristics of the land surface, by changing the surface albedo, the leaf area index (LAI), the stomatal resistance, and the surface roughness (e.g., Bonan 2008; Davin and de Noblet-Ducoudré 2010), thereby affecting regional climate conditions. Thus, LUC is thought to be a major driver of climate change on the regional scale (de Noblet-Ducoudré et al. 2012; Jia et al. 2019). To investigate the impact of LUC on the regional climate conditions, many studies were carried out in recent years, in which regional climate models (RCMs) were used to assess the different effects of LUC (Gálos et al. 2013; Davin et al. 2014; Lejeune et al. 2015; Tölle et al. 2018). However, the results of these studies are difficult to compare, since they strongly depend on the respective experimental setup. Coordinated model intercomparison studies

¿ Denotes content that is immediately available upon publication as open access.

Corresponding author: M. Breil, marcus.breil@kit.edu were mostly conducted on the global scale (de Noblet-Ducoudré et al. 2012; Kumar et al. 2013; Lejeune et al. 2017, 2018). In such studies, regional conditions are insufficiently represented, making the assessment of LUC impacts on the regional scale difficult. The Land Use and Climate Across Scales (LUCAS) initiative (Rechid et al. 2017; Davin et al. 2020) intends to close this gap by considering LUC, for the first time, within a coordinated regional climate model intercomparison project.

In this context, the role of reforestation and afforestation (herein jointly called re/afforestation) is of particular interest. Beside its important influence on the global carbon cycle, forest cover changes considerably affect the regional surface energy and water balance. In comparison to grassland, the albedo of forest is lower, absorbing more shortwave solar radiation. The LAI and the surface roughness of forest are higher, potentially increasing the turbulent heat fluxes into the atmosphere, especially evapotranspiration. Whether re/afforestation leads to a regional warming or cooling therefore depends on the ratio of the warming effect of an albedo decrease and the evapotranspirative cooling effect (e.g., Bonan 2008; Davin and de Noblet-Ducoudré 2010; Swann et al. 2012). 
Whereas a broad consensus exists about the climatic effects of re/afforestation in winter (Jia et al. 2019), the regional impact in summer is controversial (e.g., Perugini et al. 2017). In global as well as regional climate model intercomparison studies, no robust temperature response to changes in the forest cover was found in summer (de Noblet-Ducoudré et al. 2012; Kumar et al. 2013; Lejeune et al. 2017; Davin et al. 2020). Some models show warmer climate conditions, while others indicate colder conditions, especially in the midlatitudes, such as North America and Europe. Additionally, recent studies show that the temperature response to re/afforestation depends on the fraction of needleleaf to broadleaf forest (Naudts et al. 2016; Cherubini et al. 2018; Schwaab et al. 2020) and the way the vegetation characteristics are parameterized (Tölle et al. 2018). Thus, a large uncertainty prevails within the modeling community about the impact of re/afforestation on the European summer.

On the other hand, observation-based studies indicate that there is a consistent temperature response to re/afforestation in the midlatitudes. Recent studies of satellite data (deriving the radiative skin temperature from measured longwave radiation; Li et al. 2015; Alkama and Cescatti 2016; Schultz et al. 2017; Duveiller et al. 2018a; Tang et al. 2018) and eddy covariance tower measurements (deriving surface temperature from the energy budget; Lee et al. 2011; Burakowski et al. 2018) robustly show that re/afforestation leads at the surface (top of the vegetation) to a cooling during the day and a warming during the night. But until now, these observed temperature responses to re/afforestation could not be consistently reproduced within model intercomparison studies (Lejeune et al. 2017; Davin et al. 2020). This indicates that model shortcomings exist regarding the simulation of the surface energy balance (Duveiller et al. 2018b), that large-scale model results cannot fully represent local processes that are reflected in observations (Davin et al. 2020), or that such model intercomparisons exhibit a structural problem in the analysis of the simulation results.

In general, model studies focus on the analysis of nearsurface temperatures, like the 2-m temperature (e.g., de Noblet-Ducoudré et al. 2012; Lejeune et al. 2017; Davin et al. 2020). But 2-m temperature is a diagnostic quantity, defined as 2-m height above the surface (top of the vegetation), which depends on both the temperatures at the surface and at the lowest atmospheric model level. Since both temperatures are influenced by different factors, disentangling the relevant processes is difficult. The comparison of 2-m temperatures to observed surface temperatures might consequently not always be the best choice in model intercomparison studies (Winckler et al. 2019).

The goal of this study is therefore to improve the understanding of the relevant biophysical processes affected by re/afforestation by analyzing the simulated diurnal temperature cycle and energy balance in European summer. For this, an RCM ensemble created within the LUCAS initiative is used. With this LUCAS-Ensemble extreme LUC scenarios for Europe are simulated to quantify the greatest possible effect of re/afforestation on the regional climate (Davin et al. 2020). In the first experiment, Europe is completely covered with forest, where trees can realistically grow (hereinafter called
"FOREST"), and in the second experiment all forest is turned into grassland (hereinafter "GRASS"). The RCM ensemble and simulation setup are further described in section 2 .

The results of Davin et al. (2020) show that the 2-m temperature response to re/afforestation in summer is heterogeneous among the different models in the LUCAS-Ensemble. To understand the underlying biophysical processes of these diverse model results, therefore, an in-depth analysis of the effects of re/afforestation on the diurnal temperature cycle is conducted. In a first step, the biophysical processes within a single RCM (CCLM-VEG3D; see section 2a) are analyzed in detail (section 3a). By means of this analysis, all relevant processes associated with re/afforestation are identified. Based on these findings, the LUCAS-Ensemble results are assessed and the robustness and the transferability of the CCLMVEG3D results are examined (section $3 b$ ). In this way, the heterogeneous model behavior for the 2-m temperature response to the extreme re/afforestation scenario in Europe is explained. All results are discussed in section 4 and conclusions are drawn in section 5 .

\section{Methods}

\section{a. Regional multimodel ensemble}

For the two LUC scenarios GRASS and FOREST, regional climate simulations were performed using an ensemble of six different limited area models. The ensemble consists of simulations with COSMO-CLM (version COSMO5-CLM9, herein abbreviated as CCLM; Rockel et al. 2008), WRF (version 3.8.1; Skamarock et al. 2008), and the Regional Model (REMO; Jacob and Podzun 1997; Jacob et al. 2012) in different setups and different configurations. CCLM is coupled to three different LSMs: "TERRA-ML" (Schrodin and Heise 2002), "VEG3D" (Braun and Schädler 2005), and CLM4.5 (Oleson et al. 2013). REMO is coupled to the Interactive Mosaic-Based Vegetation (iMOVE) LSM (Wilhelm et al. 2014) and WRF is coupled to the two LSMs NoahMP (Niu et al. 2011) and CLM4.0 (Oleson et al. 2010). A detailed description of the LUCAS multimodel ensemble can be found in Davin et al. (2020).

All simulations within the LUCAS-Ensemble were performed for the Coordinated Downscaling Experiment-European Domain (EURO-CORDEX; Jacob et al. 2014), on a horizontal resolution of $0.44^{\circ}(\sim 50 \mathrm{~km}$; the evaluation domain, including three investigation areas, is shown in Fig. 1). The simulations were driven by ERA-Interim reanalyses (Dee et al. 2011) at the lateral boundaries and at the lower boundary over sea. The simulation period is 1986-2015. A spinup of 3-6 yr was performed before 1986 .

\section{b. Land use change scenarios}

In this study, regional climate simulations with extreme LUC scenarios for the whole European continent were performed for each member of the LUCAS-Ensemble (Fig. 2). In the first scenario, the land use classes in each grid cell of a MODIS-based present-day land cover map (Lawrence and Chase 2007) were set to forest, where forest can possibly grow (FOREST). For this purpose, the actual MODIS-based forest 


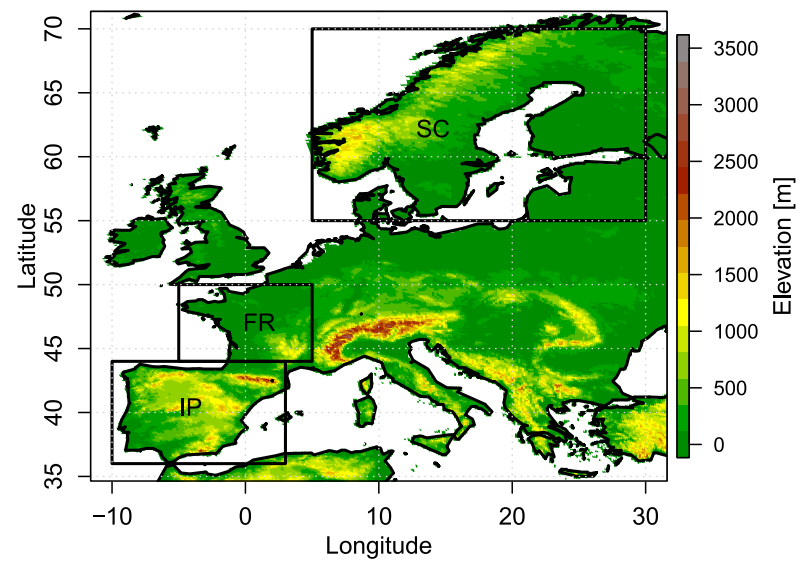

FIG. 1. European continent with the three investigation areas of France (FR), the Iberian Peninsula (IP), and Scandinavia (SC), adapted to the PRUDENCE (Christensen and Christensen 2007) regions.

coverage was extended to $100 \%$ of the vegetated soil area, whereby the proportion of the different forest types was preserved (see the fraction of needleleaf evergreen trees and broadleaf deciduous trees in Fig. 2). The bare soil fraction was not changed. Deserts and glaciers were therefore excluded from the transformation. If the forest coverage in a grid cell of the original MODIS-based land cover map was $0 \%$, the zonal mean forest composition was assigned. Thus, the resulting vegetation map represents a maximum theoretical forest coverage over Europe, considering both reforestation and afforestation potential. In the second scenario, the land use classes in each grid cell were modified in the same way but set to grassland instead of forest (see the fraction of $\mathrm{C} 3$ and $\mathrm{C} 4$ grass in Fig. 2). The European continent was therefore entirely covered by grassland (GRASS). The land surface parameters of each LUCAS-Ensemble member for these two land use change scenarios are summarized in Table 1 . A detailed description of the scenarios can be found in Davin et al. (2020).

\section{c. Model structure}

To understand differences in the simulated diurnal temperature cycles among the different LUCAS-Ensemble members, the treatment of the land-atmosphere exchange in the different LSMs is essential. Figure 3 shows a schematic structure of the interactions between the snow-free land surface and the atmosphere as described in a dual source LSM (Fig. 3a; CCLM-CLM4.5, CCLM-VEG3D, WRF-NoahMP, and WRFCLM4.0) and a bulk LSM (Fig. 3b; CCLM-TERRA and REMO-iMOVE). For both LSM types, the surface is defined as the area at which the energy fluxes between the land and the atmosphere are exchanged.

In dual source LSMs, the land surface is represented by an explicit vegetation layer. To solve the surface energy balance for this layer, the LSMs distinguish between the temperatures (and moisture contents, not shown) at leaves ( $T_{\text {leaf }}$ and $\left.q_{\text {leaf }}\right)$, in
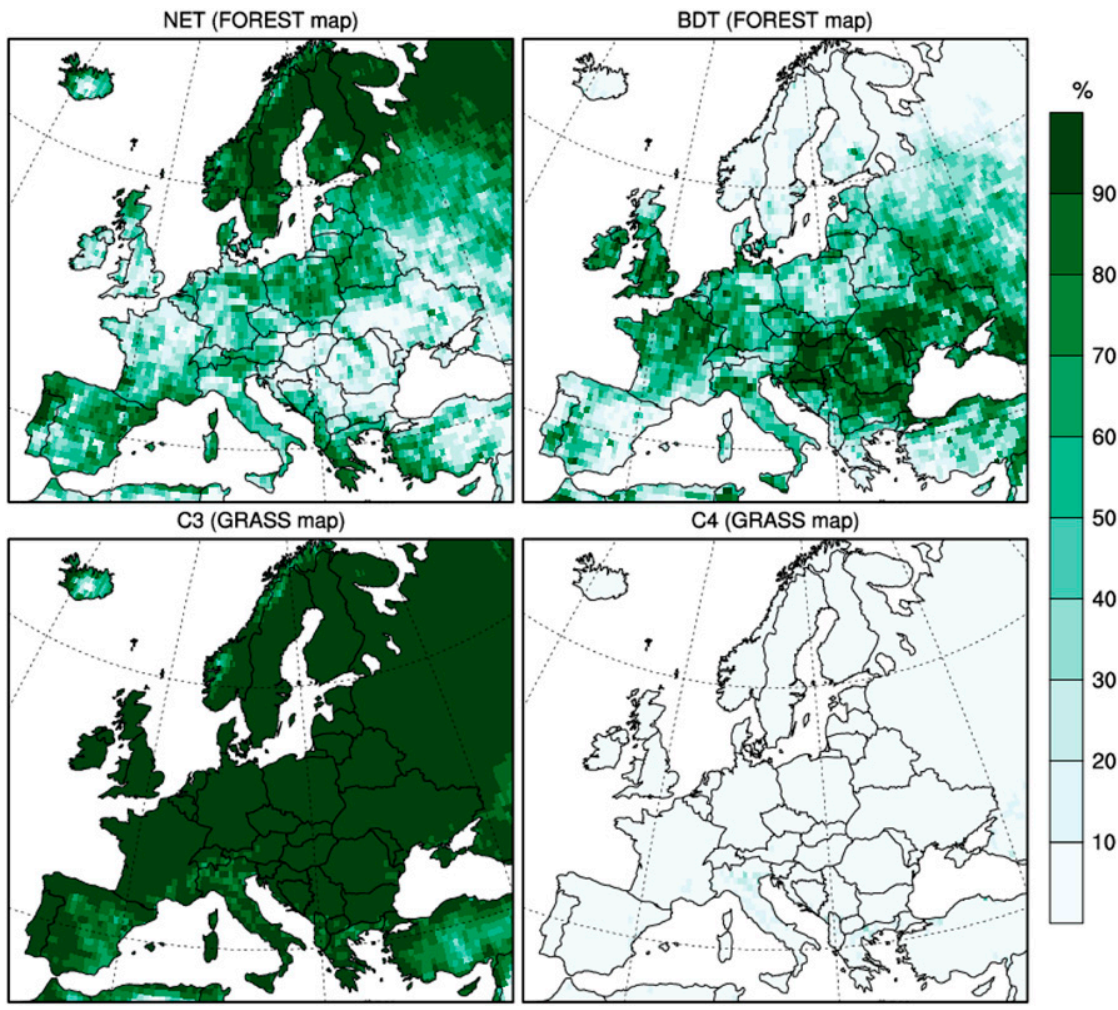

FIG. 2. Fractional vegetation maps used in the FOREST and GRASS scenarios for needleleaf evergreen trees (NET), broadleaf deciduous trees (BDT), and C3 and C4 grassland types, according to Davin et al. (2020). 
TABLE 1. Surface roughness $z_{0}$, leaf area index (LAI), and surface albedo $\alpha$ in summer (yearly maximum) used in each LUCAS-Ensemble member for needleleaf evergreen trees (NET), broadleaf deciduous trees (BDT), and C3-type grassland (C3).

\begin{tabular}{|c|c|c|c|c|c|c|c|c|c|}
\hline & \multicolumn{3}{|c|}{$z_{0}$} & \multicolumn{3}{|c|}{ LAI } & \multicolumn{3}{|c|}{$\alpha$} \\
\hline & NET & BDT & $\mathrm{C} 3$ & NET & BDT & $\mathrm{C} 3$ & NET & BDT & $\mathrm{C} 3$ \\
\hline WRF-NoahMP & 1.09 & 0.8 & 0.12 & 4 & 4.7 & 3.5 & $0.11^{\mathrm{a}}$ & $0.13^{\mathrm{a}}$ & $0.23^{\mathrm{a}}$ \\
\hline WRF-CLM4.0 & 0.7 & 0.83 & 0.048 & 3.75 & 3.38 & 2.38 & $0.11^{\mathrm{a}}$ & $0.13^{\mathrm{a}}$ & $0.21^{\mathrm{a}}$ \\
\hline CCLM-VEG3D & 1 & 0.8 & 0.03 & 9 & 8 & 4 & 0.11 & 0.15 & 0.2 \\
\hline CCLM-TERRA & 1 & 1 & 0.03 & 8 & 6 & 4.5 & 0.1 & 0.15 & 0.2 \\
\hline CCLM-CLM4.5 & 0.7 & 0.83 & 0.048 & 3.75 & 3.38 & 2.38 & $0.11^{\mathrm{a}}$ & $0.13^{\mathrm{a}}$ & $0.21^{\mathrm{a}}$ \\
\hline REMO-iMOVE & 1.4 & 1 & 0.05 & 5 & 5 & 3 & 0.155 & 0.175 & 0.21 \\
\hline
\end{tabular}

${ }^{\text {a }}$ Calculated for an exemplary leaf/stem ratio.

the canopy air ( $T_{\text {surf }}$ and $\left.q_{\text {surf }}\right)$, in the uppermost soil layer $\left(T_{\text {soil }}\right.$ and $\left.q_{\text {soil }}\right)$, and in the lowest atmospheric model layer ( $T_{\text {air }}$ and $\left.q_{\text {air }}\right)$. At the leaves, shortwave radiation $S$ is absorbed and longwave radiation $L$ is emitted upward into the atmosphere and downward to the soil. Since the vegetation layer is generally regarded as massless, the energy input out of this radiation balance cannot be stored in the leaves but has to be immediately transformed into sensible $\left(H_{\mathrm{veg}}\right)$ and latent $\left(E_{\mathrm{veg}}\right)$ heat fluxes. The amount of turbulent heat released into the atmosphere $\left(H_{\text {air }}\right.$ and $\left.E_{\text {air }}\right)$ depends on the canopy air temperature (and moisture), which is therefore regarded as the vegetation surface temperature $T_{\text {surf }}$ (and moisture $q_{\text {surf }}$ ). This surface temperature (and moisture) is a weighted mean of $T_{\text {leaf }}$, $T_{\text {soil }}$, and $T_{\text {air }}\left(q_{\text {leaf }}, q_{\text {soil }}\right.$, and $\left.q_{\text {air }}\right)$. The weights for this calculation constitute transfer coefficients, which are generally derived from the Monin-Obukhov similarity theory (Monin and Obukhov 1954) but are implemented differently among models. Based on these temperatures (moisture) the surface energy balance is solved. The residual of this surface energy balance constitutes the energy input into the soil $\left(H_{\text {soil }}\right.$ and $\left.E_{\text {soil }}\right)$.

In bulk LSMs, the land surface consists of an infinitesimal vegetation layer on top of the soil surface. In this context, the surface energy balance is solved by setting $T_{\text {soil }}$ and $q_{\text {soil }}$ to $T_{\text {surf }}$ and $q_{\text {surf }}$ and the turbulent heat fluxes within the vegetation layer are omitted. The exchange between the surface and the atmosphere is considered through the modification of the surface attributes that are used within the equations for the surface energy balance such as albedo, roughness, etc. For both LSM types the 2-m temperature $T_{2 \mathrm{~m}}$ is a diagnostic quantity depending on $T_{\text {surf }}$ and $T_{\text {air }}$. This needs to be borne in mind when interpreting the results of the modeling experiments.

\section{Model results}

Figure 4 shows the seasonal mean 2-m temperature difference in summer [June-August (JJA)] between FOREST and GRASS for all LUCAS-Ensemble members. The 2-m temperature response to re/afforestation is very heterogeneous
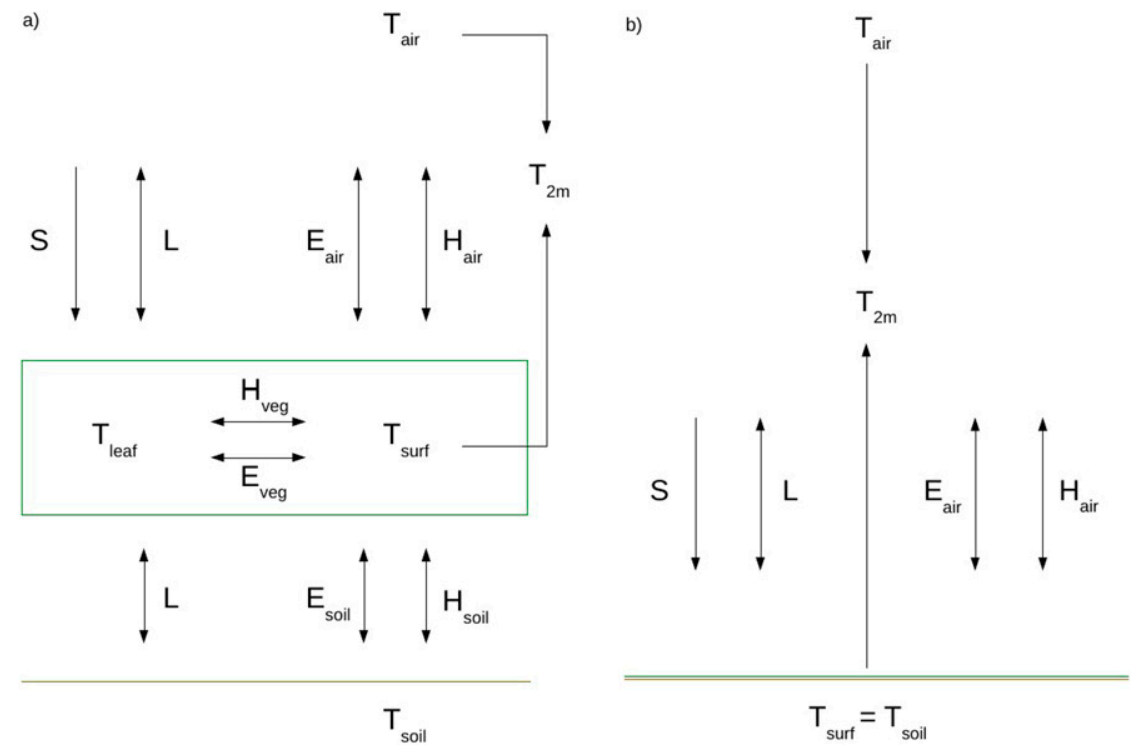

FIG. 3. Schematic structure of the interactions between the land surface and the atmosphere as described in (a) a dual-source LSM and (b) a bulk LSM. The vegetation surface is drawn in green, and the soil surface is shown in brown. 
CCLM-TERRA

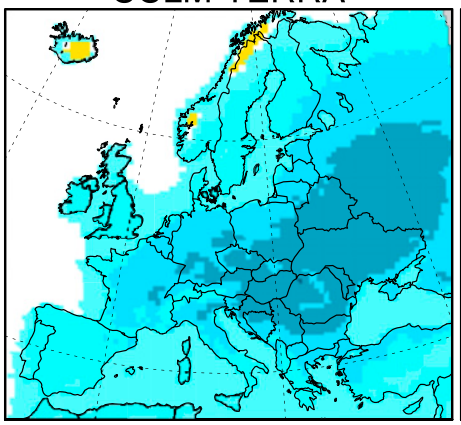

REMO-iMOVE

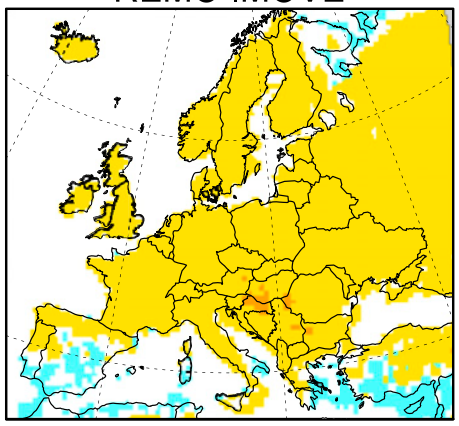

CCLM-VEG3D

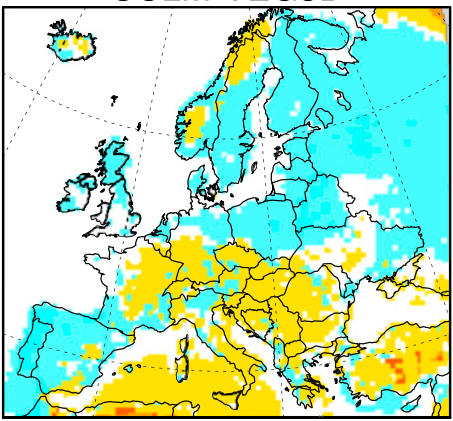

WRF-NoahMP

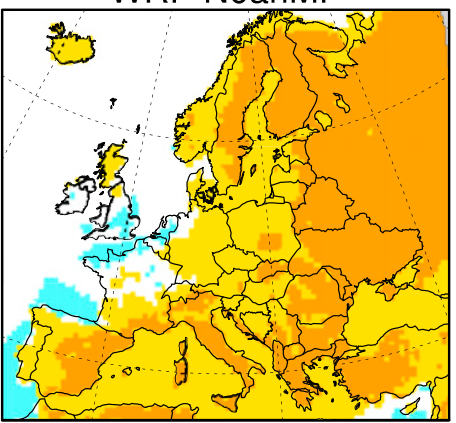

CCLM-CLM4.5

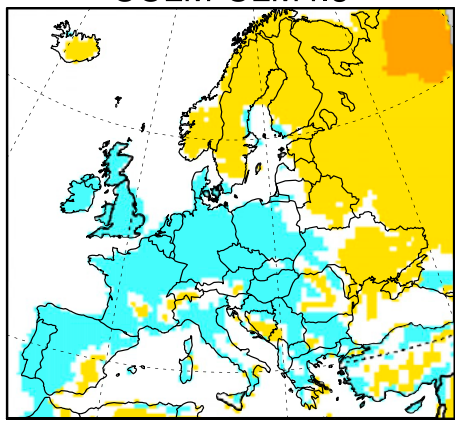

WRF-CLM4.0

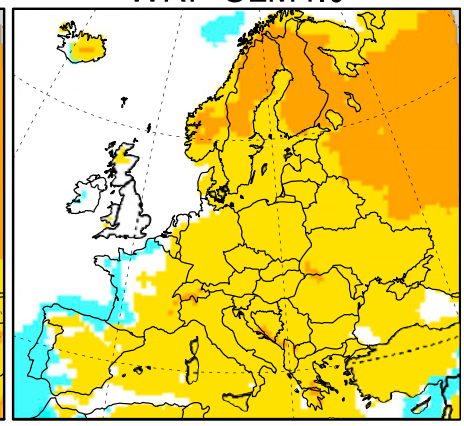

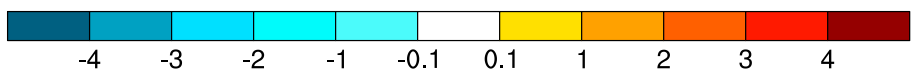

FIG. 4. Mean seasonal 2-m temperature difference in summer (JJA; FOREST minus GRASS) for all LUCASEnsemble members.

among the whole LUCAS-Ensemble. While CCLM-TERRA simulates colder climate conditions all over Europe, the whole WRF model family and REMO-iMOVE simulate a warming due to re/afforestation. Thus, the LUCAS-Ensemble results seem to reflect the same diversity in temperature responses to re/afforestation as already seen in other model intercomparison studies (e.g., de Noblet-Ducoudré et al. 2012; Lejeune et al. 2017). To reveal the mechanisms behind this heterogeneous model behavior, an in-depth analysis of the underlying biophysical processes will be conducted. Since such a detailed analysis cannot be carried out for the whole LUCAS-Ensemble, we will focus on the examination of a single RCM. Of particular interest in this context are CCLMVEG3D and CCLM-CLM4.5. In both models, the Europewide re/afforestation leads to increased 2-m temperatures in some regions and to reduced 2-m temperatures in other regions. For example, in CCLM-VEG3D a cooling is simulated for the Iberian Peninsula, while a warming is simulated for France. Thus, within a small area opposing 2-m temperature responses to a homogeneous land use change are simulated. This specific feature of the CCLM-VEG3D results opens up the possibility to investigate the underlying processes of both warming and cooling responses to re/afforestation within only one simulation. In this way, additional computing time consuming RCM simulations can be avoided.

In the following, therefore, further analysis is undertaken focusing especially on the simulation results for the Iberian
Peninsula and France in CCLM-VEG3D. The near-surface processes at the Iberian Peninsula are thereby regarded as representative for all of southern Europe, and the processes in France for all of central Europe. To be able to assess the effects of re/afforestation in northern Europe, simulation results for Scandinavia are also presented. By means of this in-depth analysis of CCLM-VEG3D, the underlying biophysical processes of opposing 2-m temperature responses can be examined in detail and illustratively described. Due to these new process insights, relevant interrelations in the climate system can be identified, on the basis of which the LUCAS-Ensemble results will be assessed and the contradictory model behavior for the 2-m temperature can be explained.

\section{a. Results of CCLM-VEG3D}

The Land Surface Model VEG3D was developed by Schädler (1990), based on a LSM developed by Deardorff (1978). The model has proven its capability to simulate realistic land-atmosphere interactions in coupled simulations with CCLM for Europe and Africa in several studies (e.g., Breil et al. 2017; Breil and Schädler 2017). It is a dual source LSM and thus the radiation and turbulent heat fluxes between the surface and the atmosphere are calculated for a massless vegetation layer. For this layer, the surface temperature is iteratively derived from the surface energy balance. Based on this surface temperature, the turbulent heat fluxes are parameterized by applying the Monin-Obukhov similarity theory. 
a)

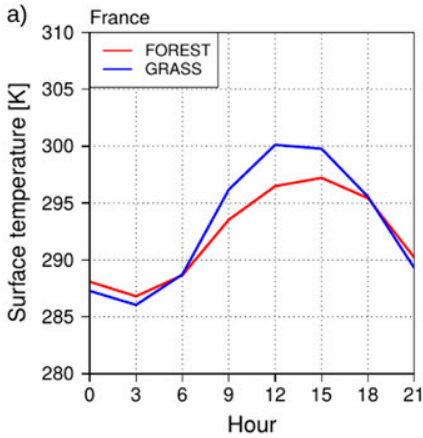

d) 310 Iberian Peninsula
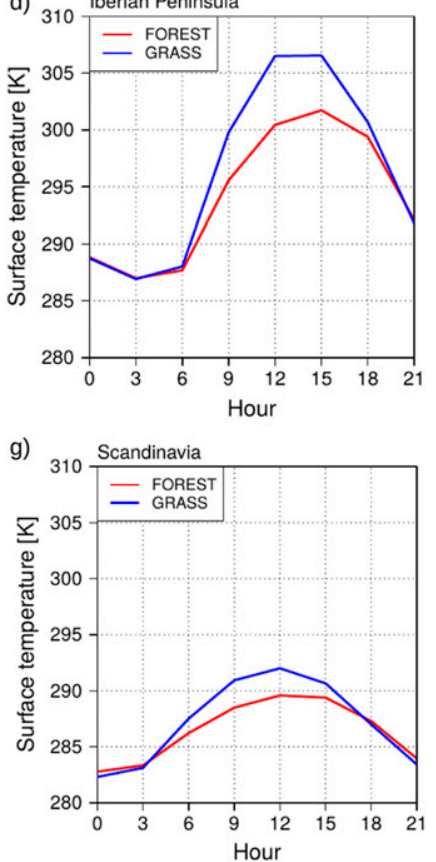

b)

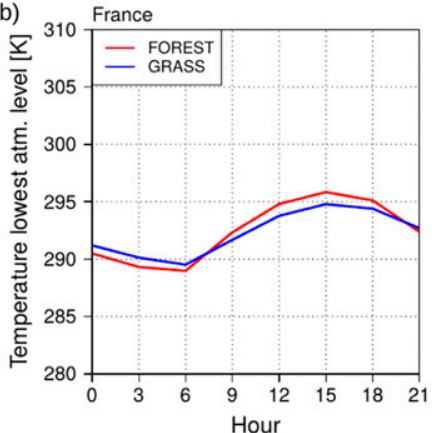

e)

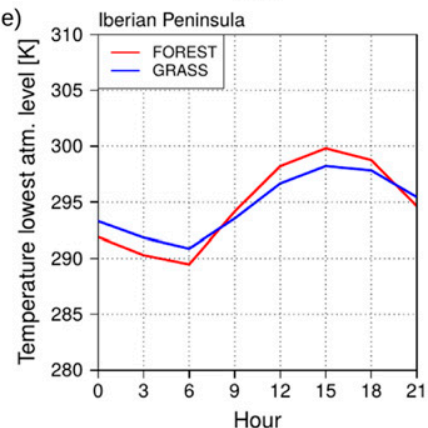

h)

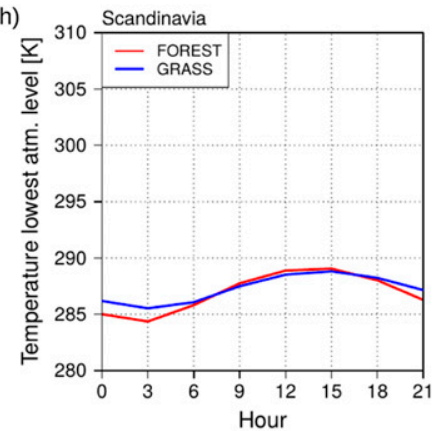

C) 310 France

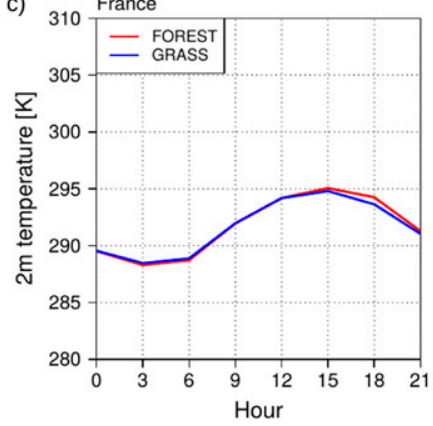

f) 310 Iberian Peninsula

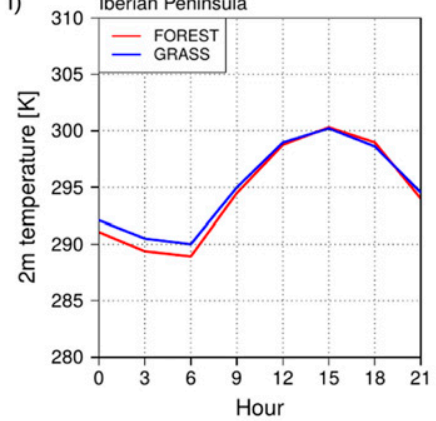

i)

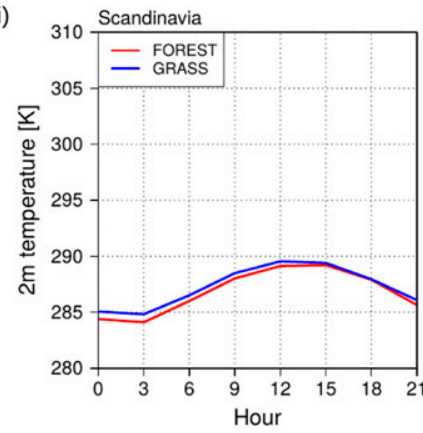

FIG. 5. CCLM-VEG3D simulation results for the mean seasonal diurnal temperature cycle in summer (left) at the surface, (center) at the lowest atmospheric model level, and (right) at 2-m height for the PRUDENCE (Christensen and Christensen 2007) regions of (a)-(c) France, (d)-(f) the Iberian Peninsula, and (g)-(i) Scandinavia. The results of the FOREST simulation are in red, and the results of the GRASS simulation are in blue.

Specific land use parameters used in VEG3D are summarized in Table 1.

\section{1) 2-M TEMPERATURE}

Figure 5 shows the diurnal temperature cycle in summer at the surface, in the lowest atmospheric model level, and for the 2-m temperature for the Prediction of Regional Scenarios and Uncertainties for Defining European Climate Change Risks and Effects (PRUDENCE; Christensen and Christensen 2007) regions of France (FR; Figs. 5a-c), the Iberian Peninsula (IP; Figs. 5d-f), and Scandinavia (SC; Figs. 5g-i). All three regions exhibit similar characteristics of the diurnal temperature cycles at the surface and in the lowest atmospheric model level, although they have different 2-m temperature responses to re/afforestation. In all regions, re/afforestation reduces the range of the diurnal temperature cycle at the surface (between $2.9 \mathrm{~K}$ in SC and $4.9 \mathrm{~K}$ in IP), with warmer conditions during the night and colder conditions during the day. In the atmosphere, the opposite occurs. In all three regions the temperature range of the diurnal cycle increases with colder temperatures during the night and with warmer temperatures during the day (between $1.4 \mathrm{~K}$ in $\mathrm{SC}$ and $3.0 \mathrm{~K}$ in IP). That means that in all regions an opposing temperature response to re/afforestation between the surface and the atmosphere is consistently simulated, but this is not reflected in the diagnostic 2-m temperature (Figs. 5c,f,i). In IP and SC colder daily mean 2-m temperatures are derived, while in FR the daily mean 2-m temperatures are warmer (Fig. 4).

In FR, the higher daily mean 2-m temperatures with re/afforestation are due to higher daily maximum 2-m temperatures in the FOREST simulation than in the GRASS run (Fig. 5c). This is because in the diagnostic calculation of the $2-\mathrm{m}$ temperature, the higher daily maximum temperatures in the atmosphere (Fig. 5b) are not compensated by the lower daily 
a)

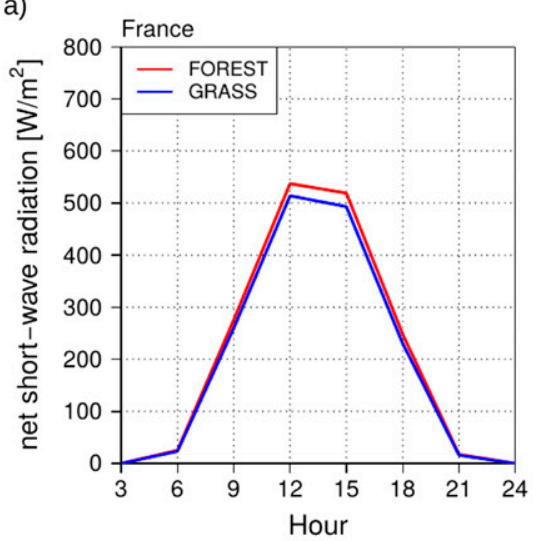

c)

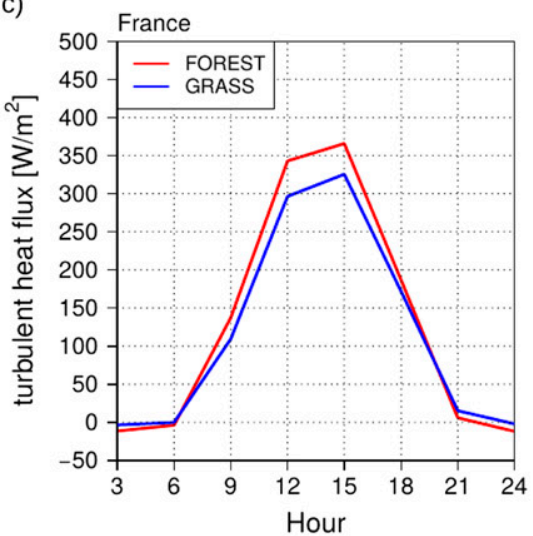

e)

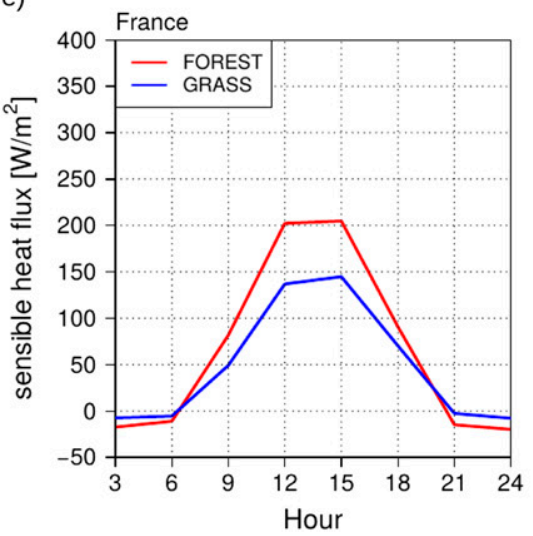

b)

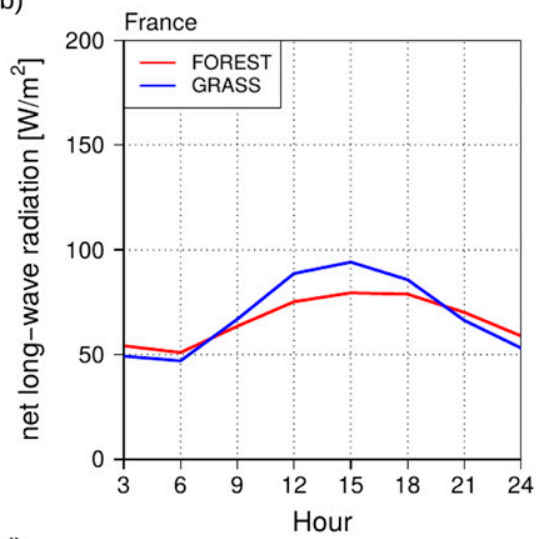

d)

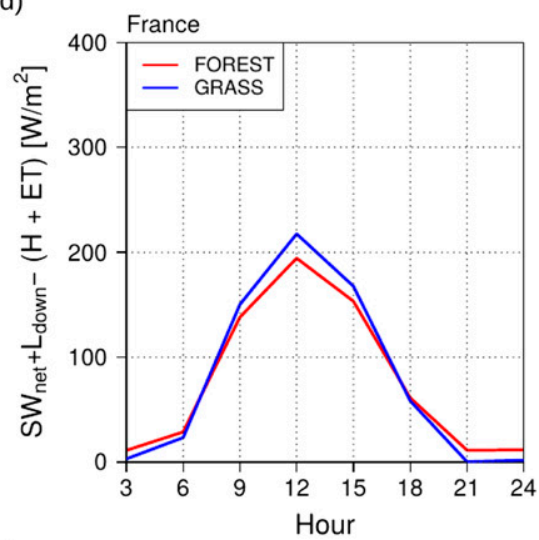

f)

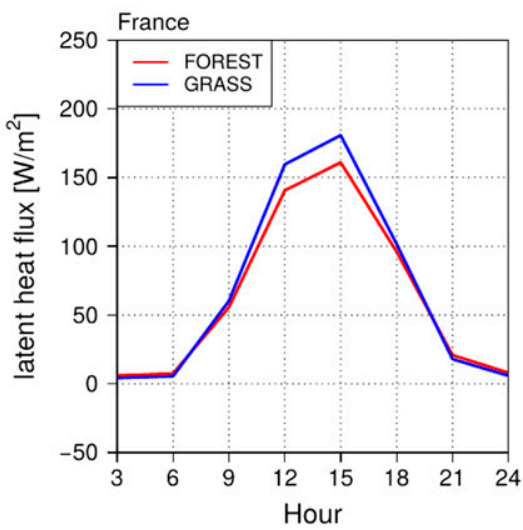

FIG. 6. CCLM-VEG3D simulation results for the mean seasonal diurnal cycle in summer of the (a) net shortwave radiation, (b) net longwave radiation, (c) turbulent heat fluxes, (d) energy amount to warm the ground (soil + surface), (e) sensible heat flux, and (f) latent heat flux for the PRUDENCE (Christensen and Christensen 2007) region of France. The results of the FOREST simulation are in red, and the results of the GRASS simulation are in blue.

maximum temperatures at the surface in FOREST (Fig. 5a). In IP, the daily mean 2-m temperatures are lower with re/afforestation because of lower nocturnal 2-m temperatures in the FOREST simulation (Fig. 5f). In this case, the lower daily minimum temperatures in the atmosphere (Fig. 5e) are not compensated by higher nocturnal surface temperatures in FOREST (Fig. 5d). In SC, the diagnostic calculation of the 2-m temperature results in lower temperatures all over the day with re/afforestation (Fig. 5i).

\section{2) SURFACE ENERGY FLUXES}

To further analyze the underlying processes of the opposing temperature response to re/afforestation between the diurnal cycles at the surface and in the lowest atmospheric model level, 
the energy fluxes at the surface are described for all three evaluation regions. The complete diurnal cycles are only shown for FR, however, since it is located in central Europe and is therefore considered to be the most representative for all of Europe. The daily minimum and maximum values for the other two regions are additionally shown and discussed in the model intercomparison in section $3 \mathrm{~b}$.

In the CCLM-VEG3D simulations the net shortwave radiation is increased with re/afforestation (about $23 \mathrm{~W} \mathrm{~m}^{-2}$ at the daily maximum in FR; Fig. 6a), due to the lower albedo values of a forest compared to grassland. But despite this increased available radiative energy input at the surface, lower daily maximum surface temperatures are simulated (Figs. 5a,d,g). However, what is decisive for the surface temperature evolution is not the available radiative energy input, but rather the amount of this energy that is used to warm the ground (surface + soil). In this context, the warming of the ground results from the residual energy amount of the incoming radiative energy input (net shortwave + longwave incoming radiation; i.e., the available energy) minus the sum of the turbulent heat fluxes (sensible + latent heat fluxes). This residual energy amount is reduced during the day in all three regions with re/afforestation (about $20 \mathrm{~W} \mathrm{~m}^{-2}$ at the daily maximum in FR; Fig. 6d). Thereby, the increased radiative energy input in FOREST is compensated by an increased sum of turbulent heat fluxes during the day (Fig. 6c). Thus, in FOREST a larger part of the available energy is sent back to the atmosphere in the form of turbulent heat fluxes, with the result that the surface temperatures are reduced during the day (Figs. 5a,d,g).

The increased turbulent heat fluxes into the atmosphere compared to GRASS are mainly caused by comparatively strong increased sensible heat fluxes (Fig. 6e). In contrast to these higher sensible heat fluxes, the latent heat fluxes are reduced with re/afforestation in CCLM-VEG3D (Fig. 6f). The lower surface temperatures during the day are consequently caused not by an increased evaporative cooling, but by an increased sum of turbulent heat (particularly sensible heat) transported into the atmosphere.

At night, the sensible heat transport is reversed and more heat is transported from the atmosphere to the surface (Fig. 6e). The reduced sensible heat fluxes during the night are in this context less pronounced than their increase during the day (from about $15 \mathrm{~W} \mathrm{~m}^{-2}$ at the daily minimum to $60 \mathrm{~W} \mathrm{~m}^{-2}$ at the daily maximum in FR). However, the energy amount to warm the ground increases at night in all three regions (about $10 \mathrm{~W} \mathrm{~m}^{-2}$ at the daily minimum in FR; Fig. 6d). This reduces the nocturnal cooling, resulting in higher nocturnal temperatures. Thus, the temperature range of the diurnal cycle at the surface is reduced due to re/afforestation as already shown in Fig. 5. These differences in the surface temperatures are also reflected in the net longwave radiation (Fig. 6b). In general, the temperature differences during the night are not as strong as during the day (Fig. 5).

While the energy amount to warm the ground (surface + soil) determines the diurnal cycle of the surface temperature, the characteristics of the diurnal temperature cycle in the lowest atmospheric model level are controlled by the change in sensible heat exchange between the surface and the atmosphere. The more sensible heat is released into the atmosphere, the warmer the lowest atmospheric model level gets. As already mentioned, more sensible heat is transported into the atmosphere during the day with re/afforestation (Fig. 6e). This results in higher daily maximum temperatures in the lowest atmospheric model level in all regions (Fig. 5). At night, as soon as the surface gets colder than the atmosphere, the direction of the sensible heat transport switches from upward to downward. The more negative values of the sensible heat fluxes therefore mean an increased nocturnal sensible heat transport from the atmosphere to the surface due to re/afforestation. Consequently, the nocturnal cooling is increased in the lowest atmospheric model level and reduced at the surface (Fig. 5). Compared to maximum deforestation (GRASS), maximum forest cover (FOREST) therefore reduces the temperature range of the diurnal temperature cycle at the surface, but intensifies the temperature range in the lowest atmospheric model level.

\section{3) MODIFIED FOREST RUN WITH VEG3D}

In the previous section, it was demonstrated that the lower surface temperatures with re/afforestation are caused by an increased transport of sensible heat from the surface into the atmosphere. But a question then arises: How can such an increased sensible heat flux evolve even though the surface temperatures are lower than for grassland? Since in this case the temperature gradient between the surface and the atmosphere, which constitutes the driving force of this flux, is also reduced, this can only be explained by turbulence enhancing characteristics of forests. To better understand the processes associated with this phenomenon, the impact of the different land use characteristics on the diurnal temperature cycle is investigated further. For this, additional FOREST simulations were performed with CCLM-VEG3D in which several land surface parameters (e.g., LAI, albedo, surface roughness) were changed, while all other land surface parameters were fixed. To save computing time, these sensitivity runs were just simulated for a single year (1979). The results of these simulations indicated that the surface temperature response to re/afforestation is most sensitive to changes in the surface roughness. This finding slightly disagrees with the results of Laguë et al. (2019), where albedo is the most sensitive parameter in the midlatitudes, but is in line with the results of Burakowski et al. (2018), who found also a clear dependency on surface roughness in the framework of their study.

Furthermore, the surface roughness values used in the FOREST and GRASS simulation in CCLM-VEG3D are within the parameter range of the whole LUCAS-Ensemble (Table 1). Thus, it is not to be assumed that the impact of the surface roughness on the simulation results in CCLM-VEG3D is either over- or underestimated in comparison to the other models, and consequently can be considered as representative for the LUCAS-Ensemble. Therefore, an additional FOREST simulation with CCLM-VEG3D was performed over the whole evaluation period 1986-2015 (with a spinup of six years), in which the surface roughness of forest was replaced by the surface roughness of grassland. All the other land use 


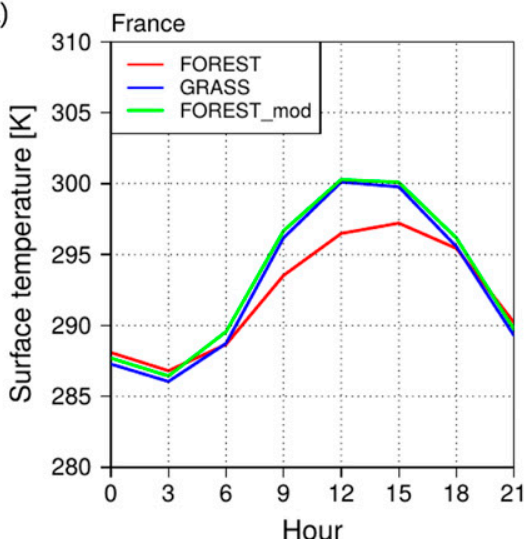

c)

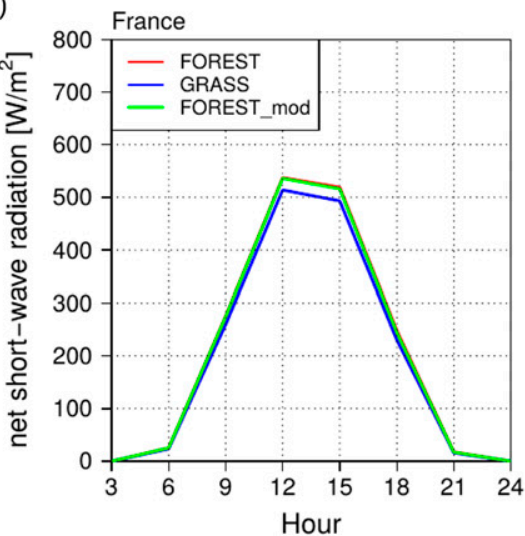

e)

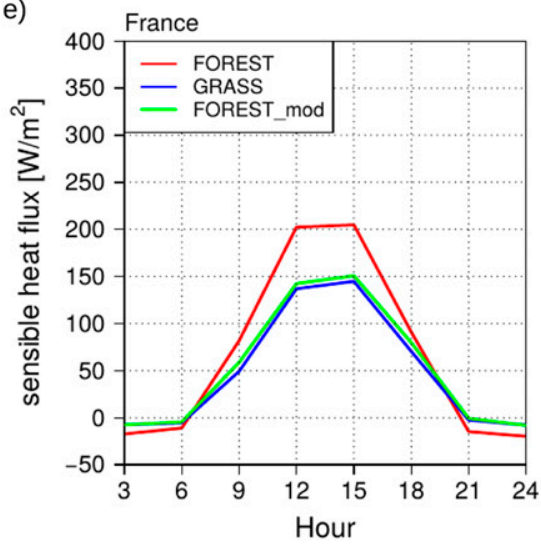

b)

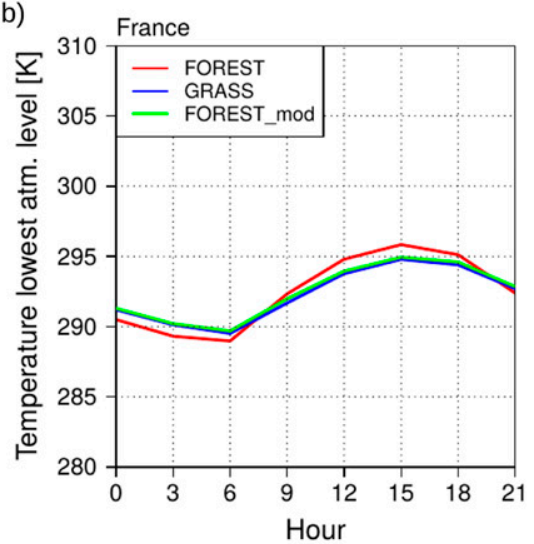

d)

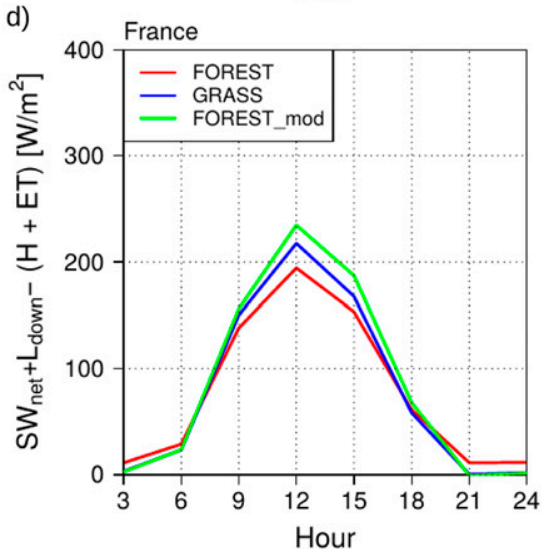

f)

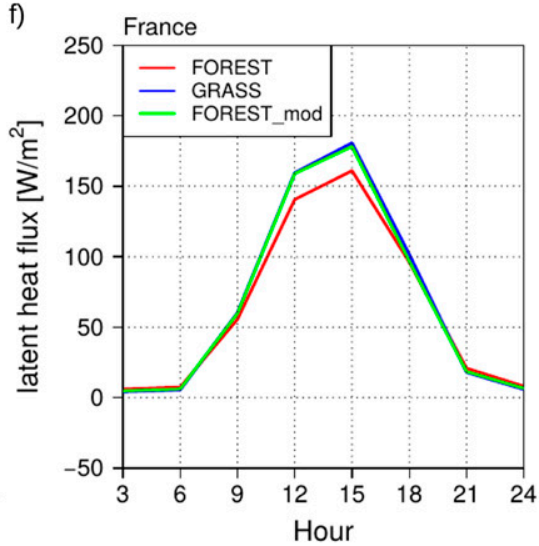

FIG. 7. CCLM-VEG3D simulation results for the mean seasonal diurnal cycle in summer of the (a) surface temperature, (b) temperature at the lowest atmospheric model level, (c) net shortwave radiation, (d) energy amount to warm the ground (soil + surface), (e) sensible heat flux, and (f) latent heat flux for the PRUDENCE (Christensen and Christensen 2007) region of France. The results of the FOREST simulation are in red, the results of the GRASS simulation are in blue, and the results of the modified FOREST run are in green.

characteristics of forest, like albedo or LAI, remained unchanged. That means that differences between the modified CCLM-VEG3D FOREST run (CCLM-VEG3D FOREST_ mod) and the standard CCLM-VEG3D FOREST simulation must be caused by differences in the surface roughness. In turn, differences between the modified run and the CCLM-VEG3D
GRASS simulation can be traced back to the unchanged land use characteristics, like albedo and LAI.

The results of this simulation show that the diurnal cycles in CCLM-VEG3D FOREST_mod behave very similar to the CCLM-VEG3D GRASS simulation and deviates considerably from the standard CCLM-VEG3D FOREST run (Figs. 7a-f). 
The diurnal temperature cycle at the surface is very similar to the CCLM-VEG3D GRASS run with increased temperatures during the day and reduced temperatures during the night compared to the standard CCLM-VEG3D FOREST simulation (Fig. 7a), according to the diurnal cycle of the energy amount to warm the ground (Fig. 7d). In comparison to the CCLM-VEG3D GRASS simulation, the surface temperatures are only slightly higher in the CCLM-VEG3D FOREST_mod run $(0.18 \mathrm{~K}$ at the daily maximum). This temperature difference is caused by the lower albedo of forest compared to grassland, leading to an increased amount of absorbed solar radiation and an increased net shortwave radiation (about $22 \mathrm{~W} \mathrm{~m}^{-2}$ at the daily maximum; Fig. 7c). The sensible heat fluxes during the day are therefore also slightly increased in the CCLM-VEG3D FOREST_mod simulation relative to CCLMVEG3D GRASS (about $6 \mathrm{~W} \mathrm{~m}^{-2}$ at the daily maximum; Fig. 7e). However, in comparison with the standard CCLMVEG3D FOREST run, the sensible heat fluxes are considerably reduced (about $54 \mathrm{~W} \mathrm{~m}^{-2}$ at the daily maximum). The temperatures in the lowest atmospheric model level during the day are therefore lower than in the standard CCLM-VEG3D FOREST simulation ( $0.9 \mathrm{~K}$ at the daily maximum) and higher than in the CCLM-VEG3D GRASS run $(0.15 \mathrm{~K}$ at the daily maximum; Fig. 7b). The latent heat fluxes in CCLM-VEG3D FOREST_mod are higher during the day than in CCLMVEG3D FOREST and also comparable to the CCLMVEG3D GRASS simulation (Fig. 7f). This demonstrates again that the surface temperatures are mainly regulated by the sum of turbulent heat fluxes transported into the atmosphere and less determined by evaporative cooling.

During nighttime, the sensible heat transport from the atmosphere to the surface is lower in the modified run than in the standard CCLM-VEG3D FOREST simulation, indicated by the smaller negative values in Fig. 7e. The nocturnal sensible heat fluxes match almost perfectly the CCLM-VEG3D GRASS run. Thus, less energy is transported from the atmosphere to the surface and the nocturnal temperatures in the lowest atmospheric model level stay higher than in the standard CCLMVEG3D FOREST run (0.88 K at the daily minimum; Fig. $7 \mathrm{~b})$. But at the surface, the nocturnal cooling is increased $(0.37 \mathrm{~K}$ colder at the daily minimum; Fig. 7a). Overall, the CCLMVEG3D FOREST_mod run behaves more like a GRASS simulation and not anymore like a FOREST run. This means that the increased turbulent heat exchange in the CCLM-VEG3D FOREST simulation, relative to the CCLM-VEG3D GRASS run, is mainly caused by the higher surface roughness of a forest compared to grassland.

\section{b. Model intercomparison}

\section{1) SuRFACE ENERGY INPUT}

Figures 8, 9, and 10 show the field mean differences between the FOREST and the GRASS simulation in summer for each member of the LUCAS-Ensemble for respectively FR, IP and SC. Positive values mean an increase and negative values indicate a reduction with re/afforestation.

In all three regions, the net shortwave radiation is increased for each member of the LUCAS-Ensemble (the range of the ensemble mean is $14-24 \mathrm{~W} \mathrm{~m}^{-2}$ for the three investigation regions; Figs. 8a, 9a, and 10a). The only exception is CCLMTERRA. Here, the net shortwave radiation is reduced with re/afforestation by a clearly increased cloud cover (Figs. 8b, 9b, and 10b). This intensified cloud cover in CCLM-TERRA is caused by a strongly increased latent heat transport into the atmosphere all over Europe. Due to this widespread increase in the latent heat fluxes, CCLM-TERRA is the only ensemble member that simulates a reduced Bowen ratio all over Europe with re/afforestation (Figs. 11a-c). The increased net shortwave radiation in the other ensemble members is mainly caused by the lower surface albedo in the FOREST simulation. In CCLM-VEG3D and CCLM-CLM4.5, the cloud cover is also slightly increased in some European regions (IP and SC in CCLM-VEG3D; IP and FR in CCLM-CLM4.5), but the reduced direct solar radiation is compensated by the lower albedo values. In WRF-CLM4.0, WRF-NoahMP, and REMO-iMOVE, the albedo effect is further intensified by a reduced cloud cover in these models.

In the LUCAS multimodel ensemble the net shortwave radiation is in all regions again transformed into an increased sensible heat exchange between the surface and the atmosphere with re/afforestation (Figs. 8c, 9c, and 10c). During the night, more sensible heat is transported from the atmosphere to the surface in all LUCAS-Ensemble members (the range of the ensemble mean is $7-12 \mathrm{~W} \mathrm{~m}^{-2}$, indicated by the negative values). During the day, more sensible heat is transported from the surface to the atmosphere, also in the whole LUCASEnsemble (the range of the ensemble mean is $32-72 \mathrm{~W} \mathrm{~m}^{-2}$ ), except for CCLM-TERRA. These reduced sensible heat fluxes in CCLM-TERRA are caused by the strongly increased latent heat fluxes (indicated by the lower Bowen ratio in Figs. 11a-c), so that in sum the turbulent heat fluxes are in all regions also increased during the day, as seen for the rest of the LUCASEnsemble (Figs. 8d, 9d, and 10d). In FR, IP, and SC, the sum of the turbulent fluxes during the day is in all ensemble members more pronounced than during the night. The increased turbulent heat exchange in the LUCAS-Ensemble compensates the increased net shortwave radiation with re/afforestation in all three regions (Figs. 8a, 9a, and 10a), so that the amount of energy to warm the ground is reduced during the day and increased during the night (Figs. 8e, 9e, and 10e). The LUCASEnsemble therefore shows the same behavior as the CCLMVEG3D simulations. The only exception is REMO-iMOVE in FR and SC (Figs. 8e and 10e). Although the changes in REMO-iMOVE are small in these regions, the energy amount to warm the ground increases consistently throughout the day with re/afforestation. That means that the increased solar energy input in FR and SC (Figs. 8a and 10a) is not compensated by the increased sum of the turbulent heat fluxes (Figs. 8d and 10d).

\section{2) SURFACE TEMPERATURES $\left(T_{\text {SURF }}\right)$}

In general, colder surface temperatures are simulated during the day with re/afforestation in the LUCAS-Ensemble (the range of the ensemble mean is $0.78-2.81 \mathrm{~K}$; Figs. 8f, 9f, and 10f) as a result of the reduced energy amount to warm the ground (Figs. 8e, 9e, and 10e). But during the night, the reversed 
a)

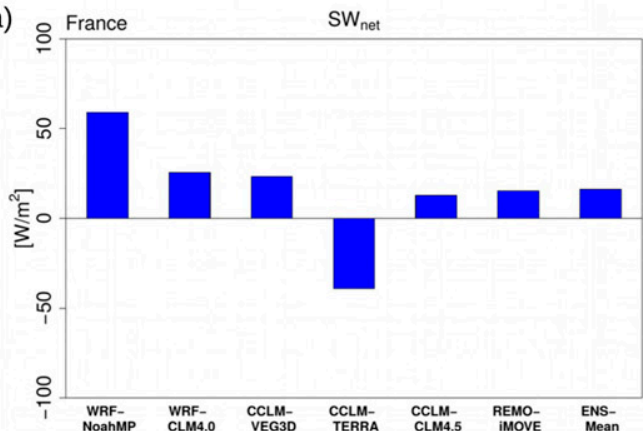

c)

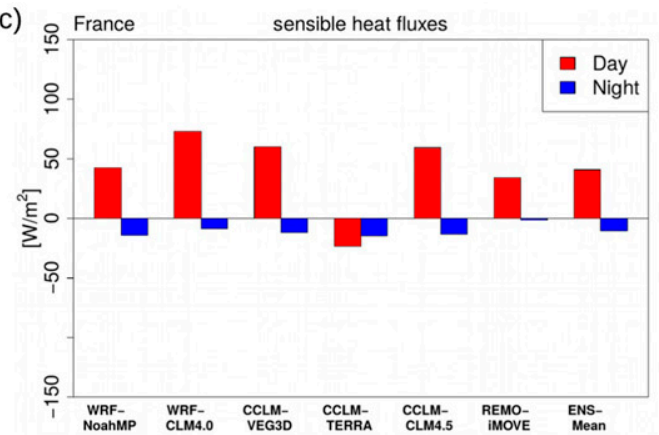

e)

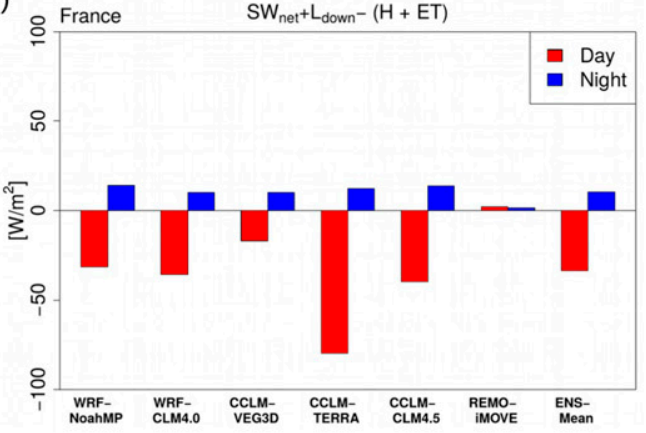

g)

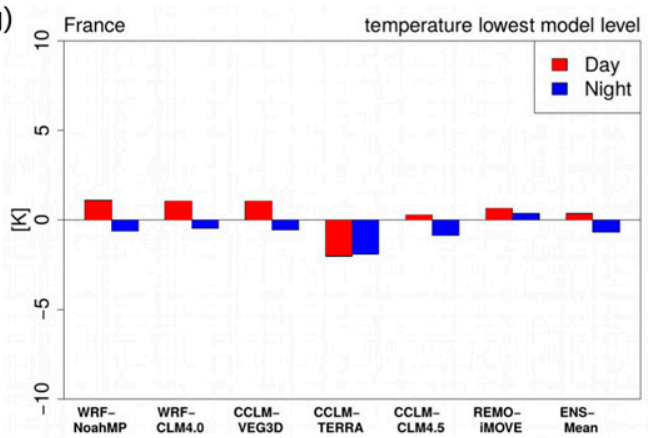

b)

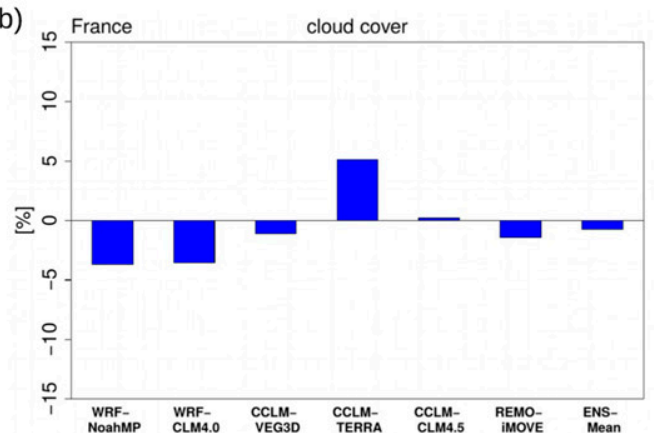

d)

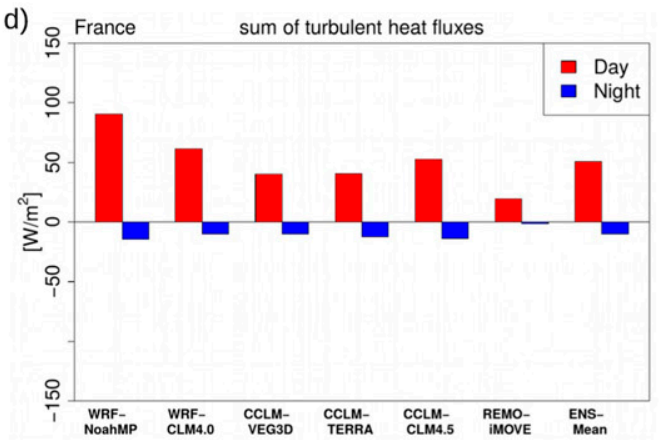

f)
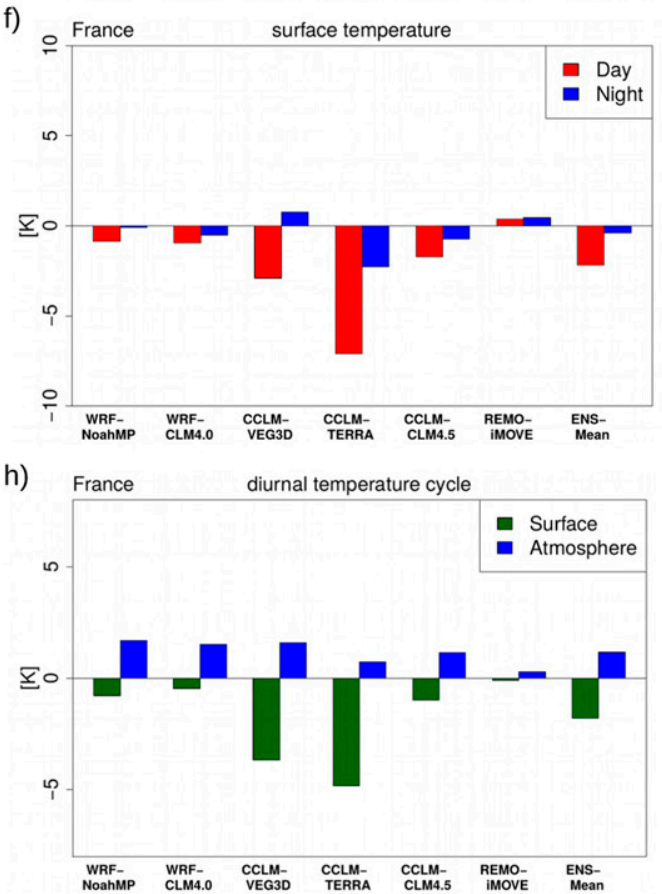

FIG. 8. Differences in the mean seasonal (a) net shortwave radiation, (b) cloud cover, (c) sensible heat fluxes, (d) sum of turbulent heat fluxes, (e) energy amount to warm the ground (surface + soil), (f) surface temperatures, (g) temperatures in the lowest atmospheric model level, and (h) diurnal temperature cycle in summer (difference between the maximum and the minimum temperature) (JJA; FOREST minus GRASS) for all LUCAS-Ensemble members. The results are shown as field means over France.

increased surface energy amount (surface + soil) does not necessarily lead in all ensemble members to warmer nocturnal surface temperatures with re/afforestation as demonstrated for CCLM-VEG3D. The higher surface energy amount merely reduces the nocturnal cooling of the surface. But this reduction of the surface cooling is not in all ensemble members strong enough to compensate the larger temperature deficit during the day and consequently, the surface temperatures at night 
a)

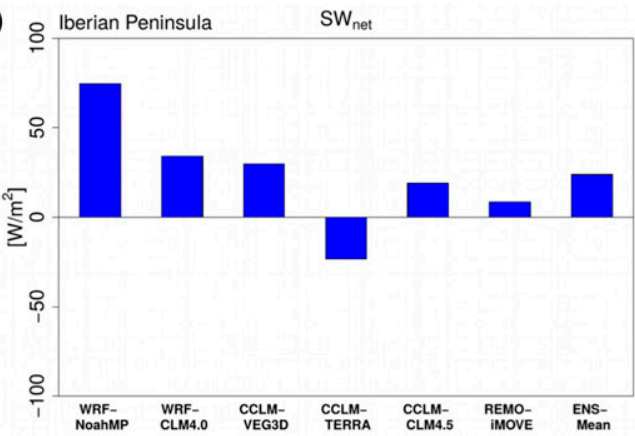

c)

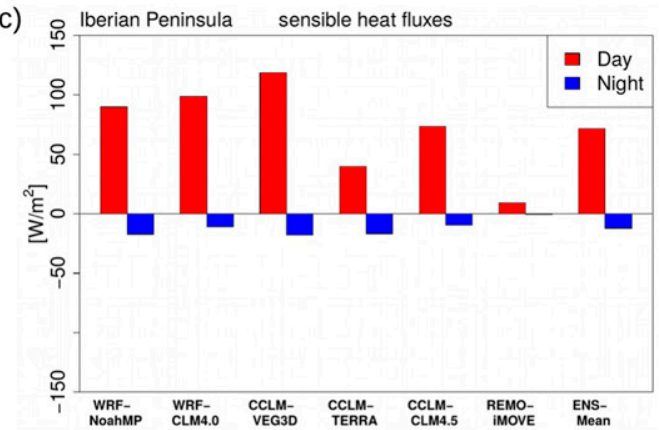

e)

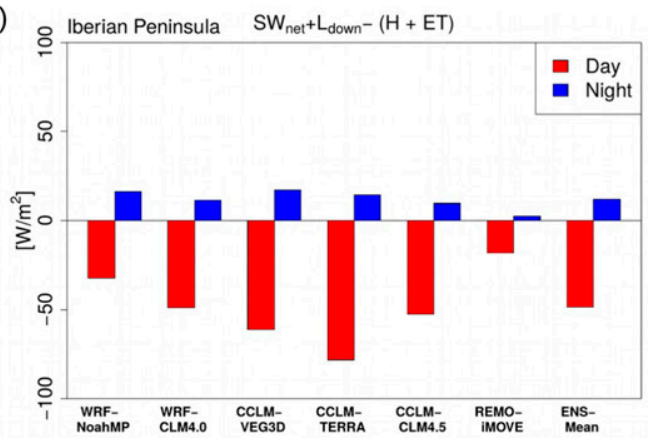

g)

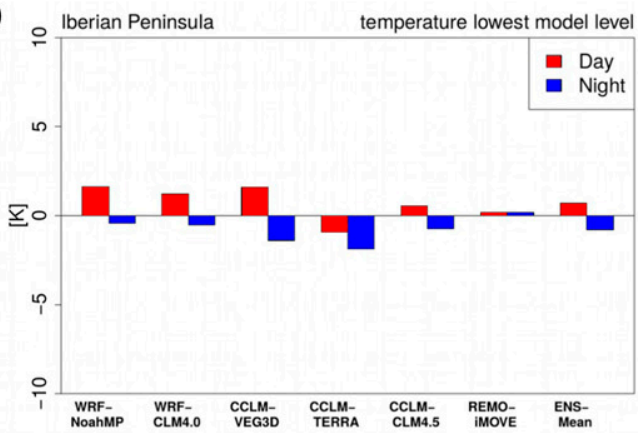

b) $\_$Iberian Peninsula cloud cover

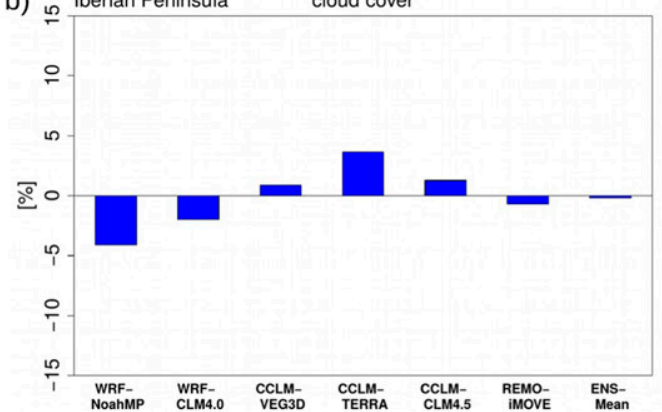

d) Iberian Peninsula sum of turbulent heat fluxes

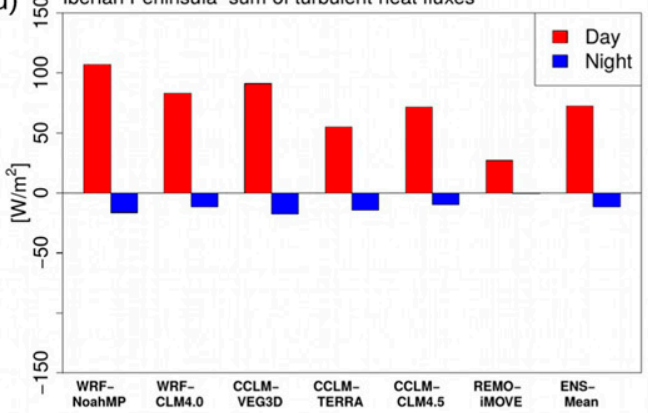

f) Iberian Peninsula surface temperature

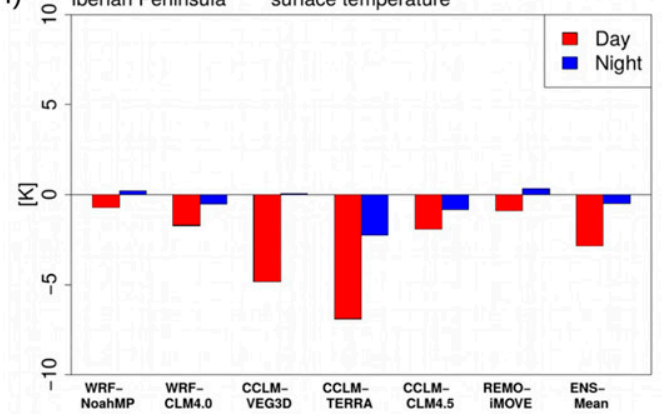

h) Iberian Peninsula diurnal temperature cycle

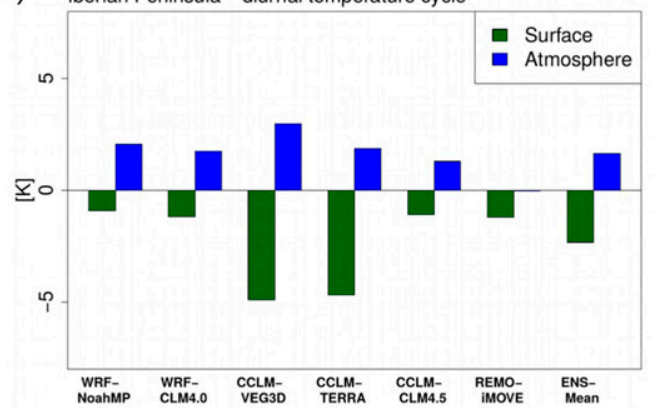

FIG. 9. As in Fig. 8, but over the Iberian Peninsula.

remain colder than in the GRASS simulation (the range of the ensemble mean is $0.07-0.49 \mathrm{~K}$; Figs. 8f, 9f, and 10f). This is the case for WRF-NoahMP, WRF-CLM4.0, CCLM-TERRA, and CCLM-CLM4.5.

However, within the LUCAS multimodel ensemble two exceptions from this general behavior occur. The first one is REMO-iMOVE in FR and SC. In contrast to the other ensemble members, the energy amount to warm the ground is increased in these regions with re/afforestation (Figs. 8e and 10e). The surface temperatures are consequently all over the day also on a higher level (Figs. 8f and 10f).

The second exceptions are the WRF-NoahMP and WRFCLM4.0 simulations in Scandinavia. Here, the model results seem to contradict the energy amount to warm the ground. In 
a)

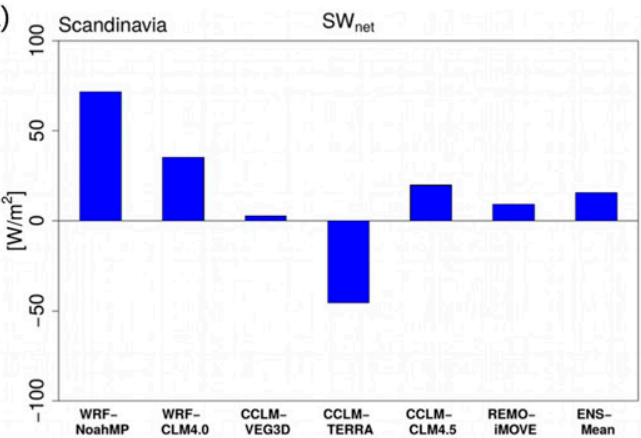

c)

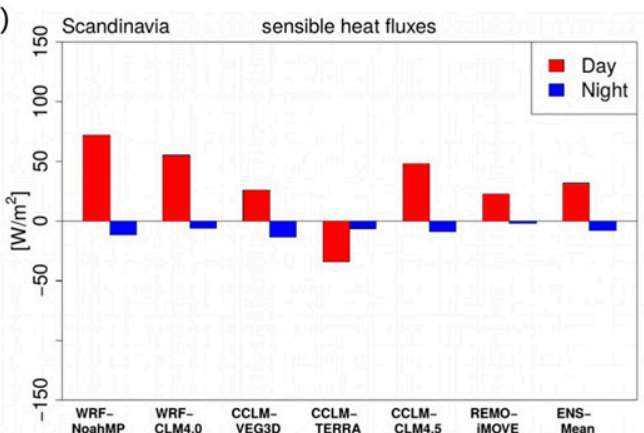

e)

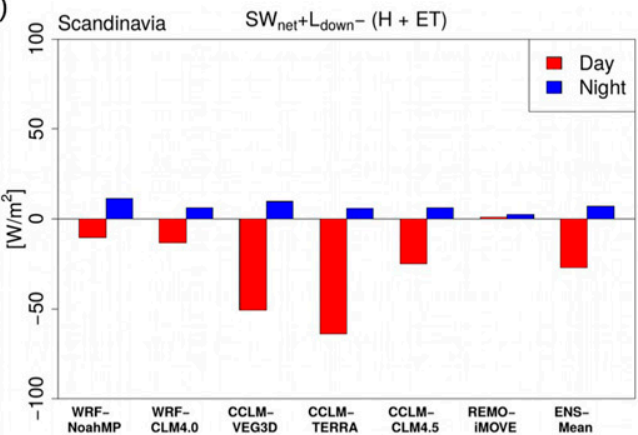

g)

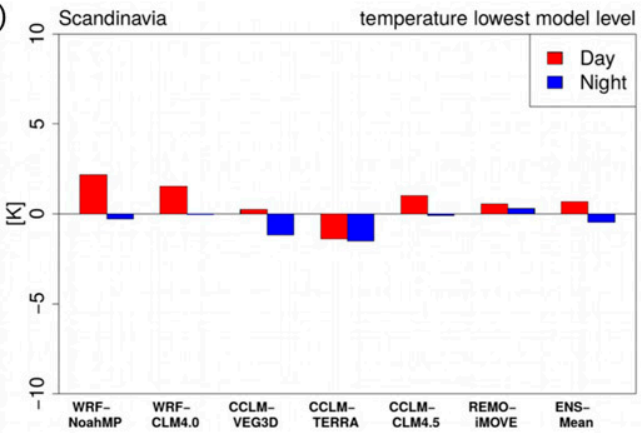

b)

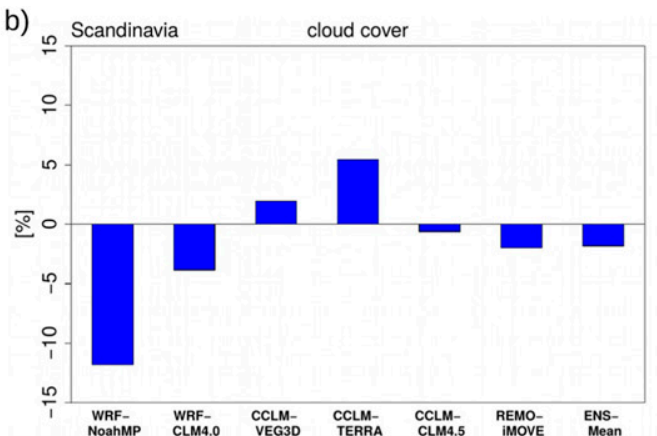

d)

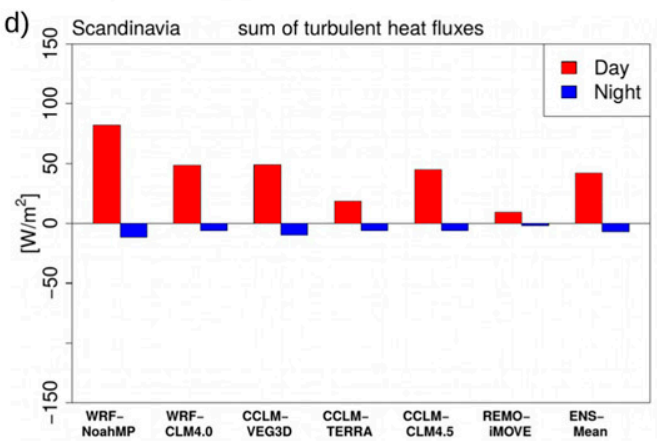

f)
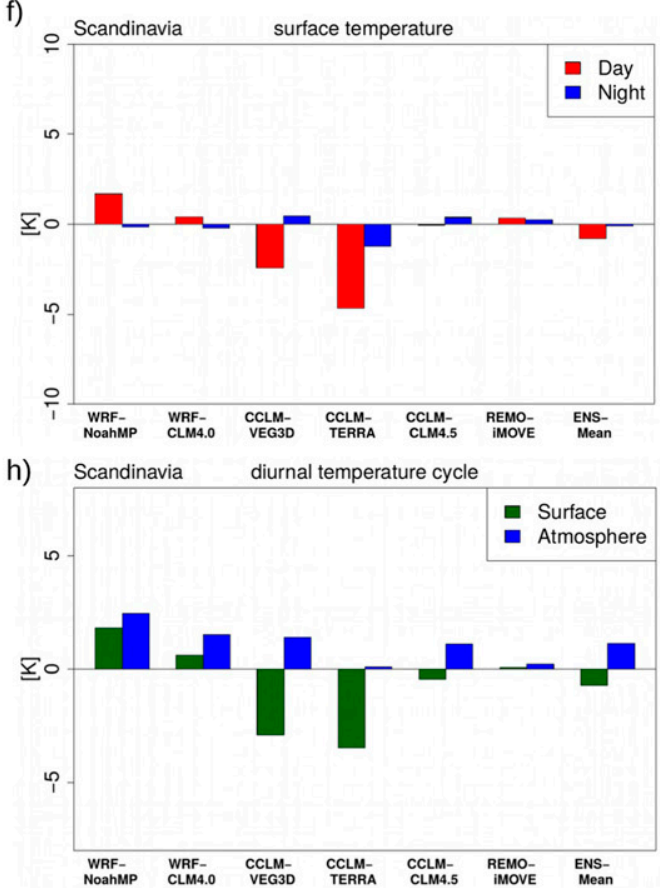

FIG. 10. As in Fig. 8, but over Scandinavia.

these models a reduced surface energy amount is simulated during the day and an increased one during the night, in line with the rest of the LUCAS-Ensemble (Fig. 10e). But the surface temperatures during the day are increased and reduced during the night with re/afforestation (Fig. 10f). This gives in these models the impression that a reduced energy amount to warm the ground during the day leads to warmer surface temperatures and an increased surface energy amount during the night to an increased nocturnal cooling.

This exceptional model behavior of WRF-NoahMP and WRF-CLM4.0 in Scandinavia is associated to the specific surface temperature calculation in the used LSMs (Fig. 3). In both models, the surface temperature is calculated for an implemented vegetation layer (dual source LSM), as a weighted 
a)

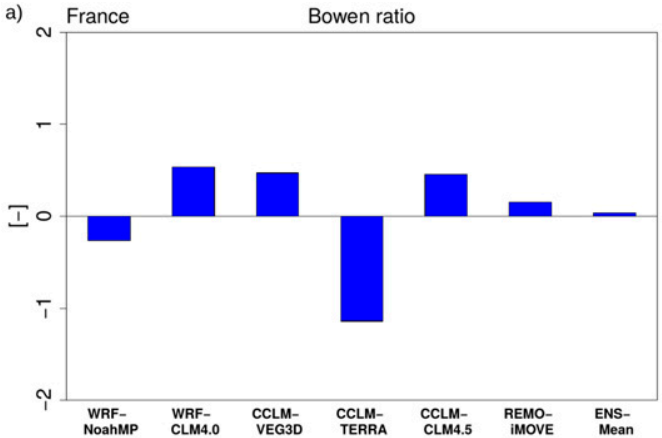

c)

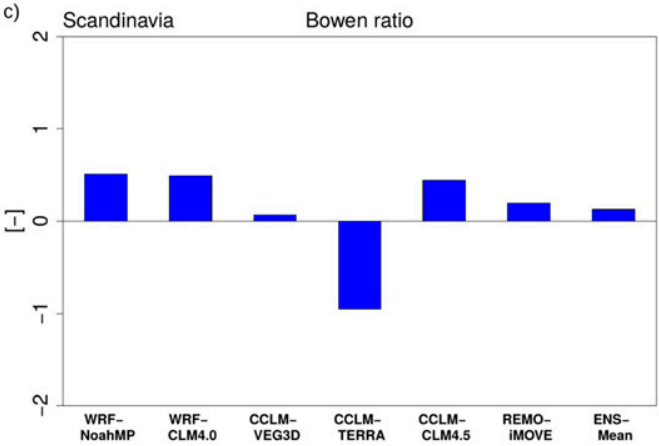

b)
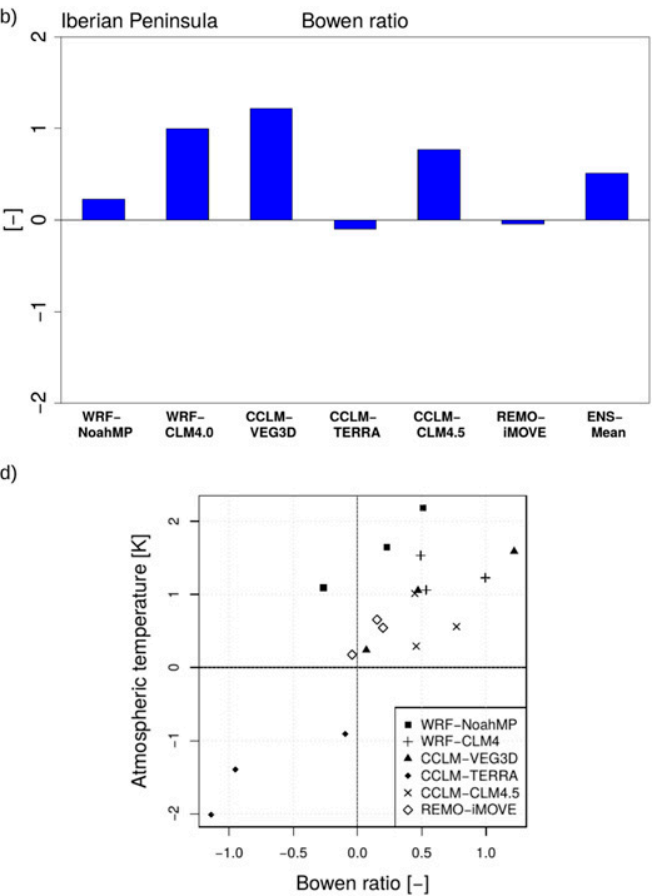

FIG. 11. Differences in the mean seasonal Bowen ratio (JJA; FOREST minus GRASS) for all LUCAS-Ensemble members. The results are shown as field means over (a) France, (b) the Iberian Peninsula, and (c) Scandinavia. Also shown is (d) the relationship between changes in the Bowen ratio with re/afforestation and the changes in temperature in the lowest atmospheric model level.

mean of the leaf temperature, the temperature in the uppermost soil layer, and the temperature in the lowest atmospheric model level. In this context, the transfer coefficients depend on vegetation parameters like, for instance, the surface roughness. A high surface roughness leads to a high transfer coefficient, increasing the sum of the turbulent heat fluxes between the canopy and the atmosphere, as seen in the results of the FOREST simulations [section 3a(3)]. The intensified sum of the turbulent heat transport into the atmosphere reduces the temperature gradient between the "warm" canopy and the "cold" atmosphere relative to the GRASS simulations. At the same time, less energy is transported to the soil, which is reflected in a reduced residual of the surface energy balance and a reduced soil heating.

Now, the WRF-NoahMP and WRF-CLM4.0 results in Scandinavia constitute a special case of this specific surface temperature calculation. In this region, the sensible heat flux into the atmosphere is in both models strongly increased in FOREST (Fig. 10c). The proportion of the turbulent heat released into the atmosphere is therefore increased and less energy is transported to the soil. This results in a reduced diurnal temperature range in the uppermost soil level in Scandinavia (as shown, for instance, for WRF-NoahMP; Fig. 12a). The temperature gradient between the surface and the atmosphere is consequently further reduced. For the calculation of the surface temperature, the weight of the temperature in the lowest atmospheric model level is getting stronger compared to the weight of the soil temperature. The diurnal cycle of the surface temperature (Fig. 12b) is therefore getting closer to the one of the lowest atmospheric model level (Fig. 12c). Thus, the increased diurnal temperature range at the surface just reflects the intensified turbulent heat exchange with the atmosphere for these two models in Scandinavia, giving the impression of an inconsistent model behavior. But in fact, in Scandinavia the same physical processes take place as in the rest of Europe, as shown by the damped diurnal cycle of the of the uppermost soil level with re/afforestation (Fig. 12a). The processes are even more pronounced in WRF-NoahMP and WRF-CLM4.0 (Fig. 10c).

This intensified coupling between the surface and the atmosphere with re/afforestation in Scandinavia is caused by two factors. First, in this region the surface roughness is higher than in the rest of Europe, since the forest comprises primarily needleleaf trees with higher roughness values, in contrast to the otherwise dominating broadleaf trees (Fig. 2). Second, re/afforestation leads in WRF-NoahMP and WRF-CLM4.0 to the strongest reduction of the cloud cover in Scandinavia in the LUCAS-Ensemble (Fig. 10b). This results, in combination with the low albedo values of needleleaf trees, in the strongest relative increase in net shortwave radiation with re/afforestation in the whole ensemble. Because of the high surface roughness in Scandinavia, WRF-NoahMP and WRF-CLM4.0 are able to transform this additional energy amount into the strongest relative increase of sensible heat fluxes with re/afforestation in all models and regions.

The general surface temperature characteristics of the LUCAS-Ensemble in the three investigation areas FR, IP, and 


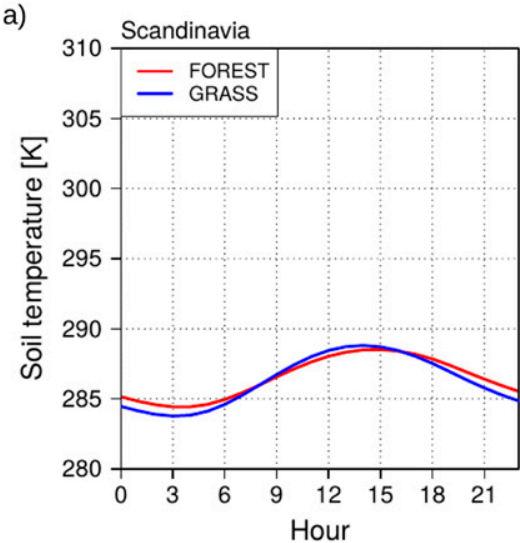

c)

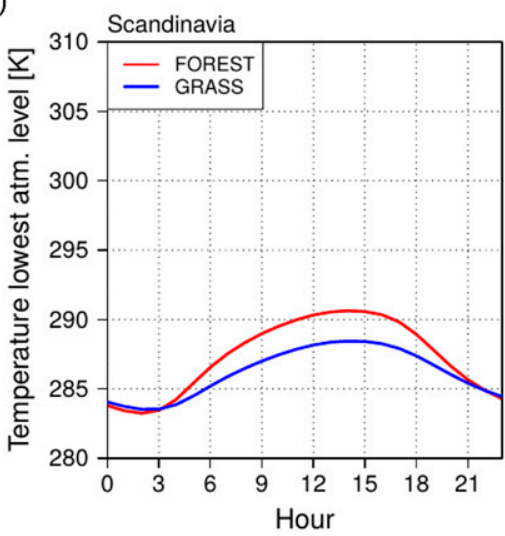

b)

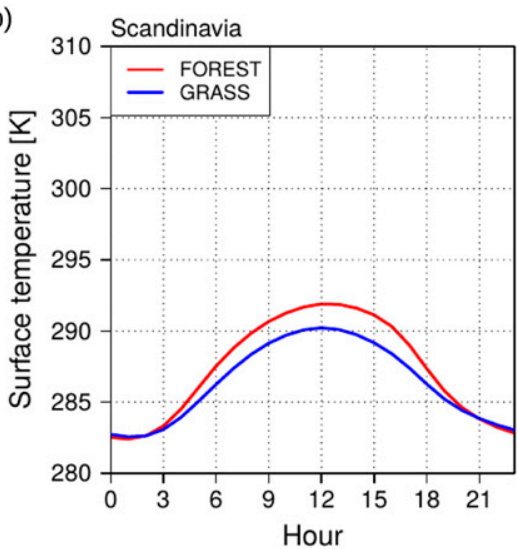

FIG. 12. WRF-NoahMP simulation results for the mean seasonal diurnal cycle in summer of (a) the temperature in the uppermost soil layer, (b) the surface temperature, and (c) the temperature in the lowest atmospheric model level for the PRUDENCE (Christensen and Christensen 2007) region of Scandinavia.

SC (Figs. 8f, 9f, and 10f) are also reflected in a spatial difference plot (FOREST minus GRASS) of the mean daily maximum temperature (JJA) at the surface (Fig. 13). While in CCLMTERRA, CCLM-VEG3D, and CCLM-CLM4.5 colder daily maximum surface temperatures are simulated all over Europe, warmer temperatures are simulated in REMO-iMOVE (except for IP). In WRF-NoahMP and WRF-CLM4.0 a surface cooling is simulated with re/afforestation in central and southern Europe, but a warming in northern Europe, which is again in line with the results of the three investigation areas (Figs. 8f, 9f, and 10f). Warmer surface temperatures are also simulated in eastern Europe in both WRF models. There, the same chain of processes takes place as described above for the warmer daily surface temperatures in Scandinavia.

\section{3) TEMPERATURES IN THE LOWEST ATMOSPHERIC} MODEL LEVEL $\left(T_{\text {AIR }}\right)$

The increased sensible heat transport into the atmosphere during the day (Figs. 8c, 9c, and 10c) leads in all models to warmer daily maximum temperatures in the lowest atmospheric model level with re/afforestation (the range of the ensemble mean is $0.35-0.71 \mathrm{~K}$; Figs. $8 \mathrm{~g}$, $9 \mathrm{~g}$, and $10 \mathrm{~g}$ ). Again, the only exception is CCLM-TERRA, with its reduced sensible heat fluxes and the resulting lower atmospheric temperatures. The intensity of the warming in the lower atmosphere highly depends in this context on the proportion of the latent heat fluxes to the total turbulent heat fluxes in the respective models. The most common way to measure this proportion is the Bowen ratio. An increase in the Bowen ratio with re/afforestation (i.e., a reduced proportion of the latent heat fluxes to the total turbulence) generally leads to a warming, a reduced Bowen ratio, and a cooling in the lower atmosphere (Fig. 11d). The correlation between the Bowen ratio and the temperatures in the lowest atmospheric model level is $r=0.8$ for the whole LUCAS-Ensemble. Only for WRF-NoahMP in FR (Fig. 11a) and for REMO-iMOVE in IP (Fig. 11b), a reduced Bowen ratio with re/afforestation results in increased atmospheric temperatures (Fig. 11d). But beside the increased latent heat fluxes, also the sensible heat fluxes are in these regions enhanced (but not as pronounced; Figs. 8c and 9c) and thus the temperature in the lowest atmospheric model level is in these simulations also increased.

This consistent model behavior among the LUCAS-Ensemble for the three investigation areas FR, IP, and SC (Figs. 8g, 9g, and $10 \mathrm{~g}$ ) is also reflected in a spatial difference plot (FOREST minus GRASS) of the mean daily maximum temperature 

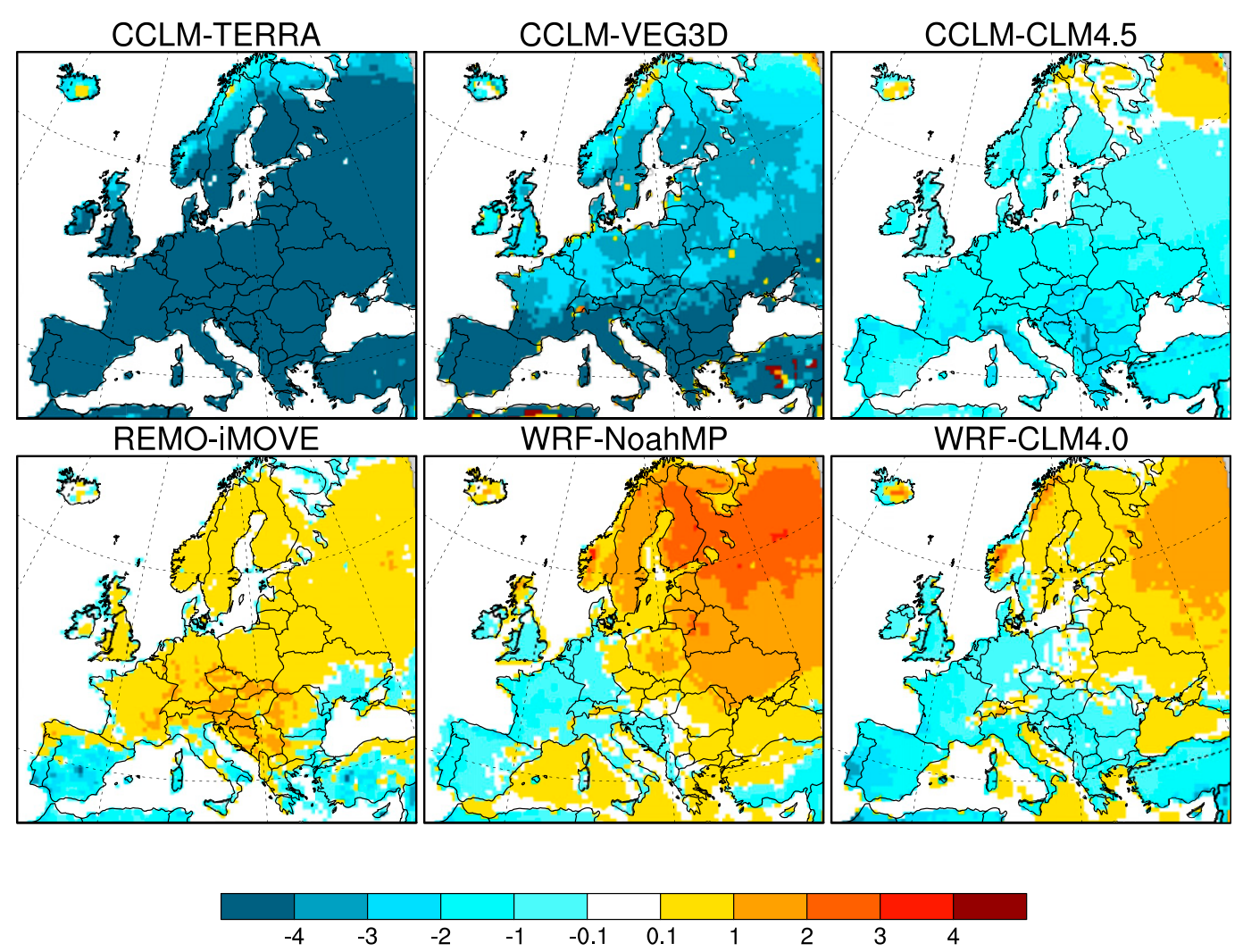

FIG. 13. Mean seasonal difference in daily maximum surface temperature in summer (JJA; FOREST minus GRASS) for all LUCAS-Ensemble members.

(JJA) in the lowest atmospheric model level (Fig. 14). Except for CCLM-TERRA, all ensemble members simulate all over Europe warmer daily maximum temperatures with re/afforestation.

At night, all models simulate an increased sensible heat transport from the atmosphere to the surface (Figs. 8c, 9c, and 10c). Thus, the atmospheric temperatures are more strongly reduced with re/afforestation in the whole LUCAS-Ensemble (Figs. 8g, 9g, and 10g). This situation leads to, in all ensemble members, colder nocturnal temperatures in the lowest atmospheric mode level (the range of the ensemble mean is $0.45-$ $0.79 \mathrm{~K}$ ). Only in REMO-iMOVE the nocturnal cooling is not strong enough to compensate the temperature surplus during the day and consequently the temperatures remain warmer during the night with re/afforestation.

Therefore, in the whole LUCAS-Ensemble, an increased sensible heat exchange all over the day (Figs. 8c, 9c, and 10c) and a damped diurnal cycle of the energy amount to warm the ground (Figs. 8e, 9e, and 10e) is consistently simulated all over Europe with re/afforestation (except for REMO-iMOVE in FR and SC). This results in a consistently simulated increase of the diurnal temperature range in the lowest atmospheric model level (about $1.1-1.7 \mathrm{~K}$ in the ensemble mean; Figs. $8 \mathrm{~h}, 9 \mathrm{~h}$, and $10 \mathrm{~h}$, blue) and a reduction of the diurnal temperature range at the surface (the range of the ensemble mean is $0.7-2.3 \mathrm{~K}$; Figs. $8 \mathrm{~h}, 9 \mathrm{~h}$, and 10h, green) in all LUCAS-Ensemble members. The only exceptions are an increased diurnal temperature range at the surface in Scandinavia in WRF-NoahMP and WRF-CLM4.0 (due to a strongly intensified relative sensible heat exchange with the atmosphere) and in REMO-iMOVE (caused by an increased surface energy amount), as already mentioned in section $3 b(2)$.

This model-specific behavior of REMO-iMOVE and both WRF models is also reflected in a spatial difference plot (FOREST minus GRASS) of the diurnal temperature range at the surface for all LUCAS-Ensemble members (Fig. 15). Again, for WRF-NoahMP and WRF-CLM4.0 in eastern Europe, the same temperature response to re/afforestation is simulated as in Scandinavia. In CCLM-TERRA, CCLM-VEG3D, and CCLM-CLM4.5 a reduced diurnal temperature range at the surface is consistently simulated all over Europe. In the lowest atmospheric model level, a Europe-wide increase in the diurnal temperature range is consistently simulated in all LUCASEnsemble members (Fig. 16).

\section{Discussion}

Within the LUCAS-Ensemble, different 2-m temperature responses to re/afforestation are simulated in summer. Thus, the multimodel ensemble results reflect the same diverging model behavior as in other model intercomparison studies, which reported both warmer and colder near-surface temperatures (2-m temperature) with re/afforestation (de NobletDucoudré et al. 2012; Kumar et al. 2013; Lejeune et al. 2017; 
CCLM-TERRA

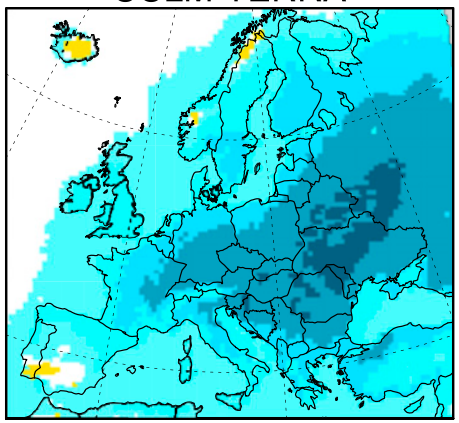

REMO-iMOVE

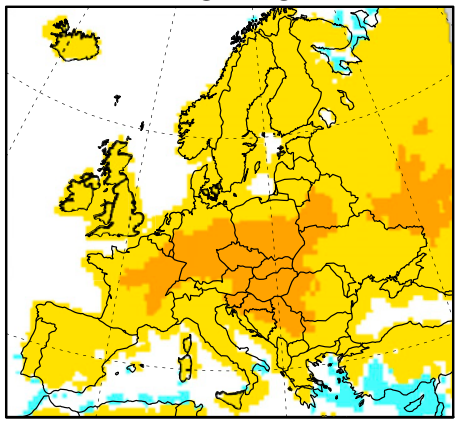

CCLM-VEG3D

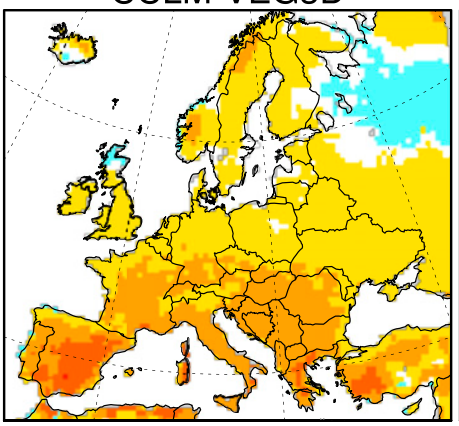

WRF-NoahMP

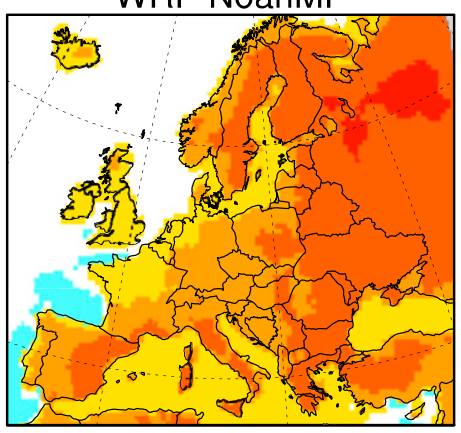

CCLM-CLM4.5

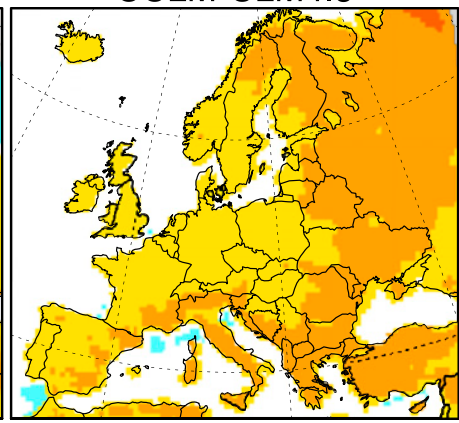

WRF-CLM4.0

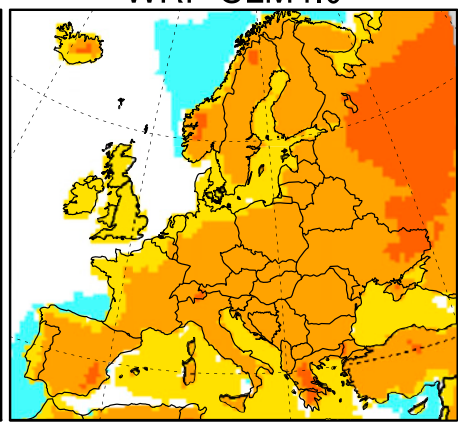

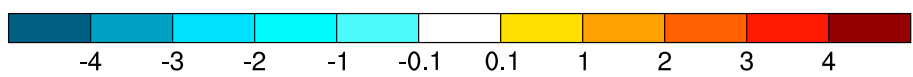

FIG. 14. As in Fig. 13, but for maximum temperature in the lowest atmospheric model level.

Davin et al. 2020). However, an analysis of the diurnal temperature cycles at the surface and at the lowest atmospheric model level revealed that this inconsistent model behavior is potentially due to the diagnostic 2-m temperature. For instance, regions with opposing 2-m temperature responses to re/afforestation in CCLM-VEG3D showed a consistent behavior of the diurnal temperature cycles at the surface and in the lowest atmospheric model level. The same consistency is seen in all members of the LUCAS-Ensemble, with a subdued diurnal temperature cycle at the surface and an amplified one in the lowest atmospheric model level with re/afforestation. Due to these opposing temperature responses to re/afforestation, the diagnostic calculation of the 2-m temperatures can be misleading and overlays the actual effects of LUC. The large spread of near-surface temperature responses to re/afforestation among different model studies, therefore, can potentially be explained by the interpretation of the 2-m temperature (Lejeune et al. 2017; Davin et al. 2020), instead of using the temperatures at the surface and in the lowest atmospheric model level. Thus, this study supports the results of other studies, critically discussing the interpretation of the 2-m temperature in the context of LUC (Meier et al. 2018; Winckler et al. 2019).

In general, re/afforestation leads in the LUCAS multimodel ensemble to a consistently increased net shortwave radiation, due to the lower albedo values of a forest compared to grassland. But this higher amount of absorbed solar energy does generally not result in higher surface temperatures during the day. The additional energy input at the surface is in almost all models compensated by an enhanced transport of turbulent heat fluxes (sensible + latent heat fluxes) into the atmosphere. Therefore, the question of whether re/afforestation leads to a warming or a cooling of the surface depends on the ratio between the incoming solar radiation at the surface and the outgoing sum of sensible and latent heat fluxes into the atmosphere (Bonan 2008; Davin and de Noblet-Ducoudré 2010). Since these processes are differently weighted in the single $\mathrm{RCMs}$, the surface cooling during the day with re/afforestation is differently pronounced within the LUCAS-Ensemble. But in general, the LUCAS-Ensemble confirms the results of observation-based studies, showing a cooling of the surface during the day and a warming during the night with re/afforestation (Lee et al. 2011; Li et al. 2015; Alkama and Cescatti 2016; Schultz et al. 2017; Burakowski et al. 2018; Duveiller et al. 2018a; Tang et al. 2018).

To understand the underlying processes of this reduced diurnal temperature range at the surface with re/afforestation, an additional CCLM-VEG3D FOREST simulation, using the surface roughness of grassland instead of forest, was performed. In the modified CCLM-VEG3D FOREST_mod simulation, the sum of the turbulent heat fluxes is considerably reduced compared to the standard CCLM-VEG3D FOREST run. Its diurnal temperature cycle is consequently amplified at the surface and subdued in the atmosphere. Since the surface roughness is the only changed quantity in the modified CCLMVEG3D run, differences in the turbulent heat exchange, and 

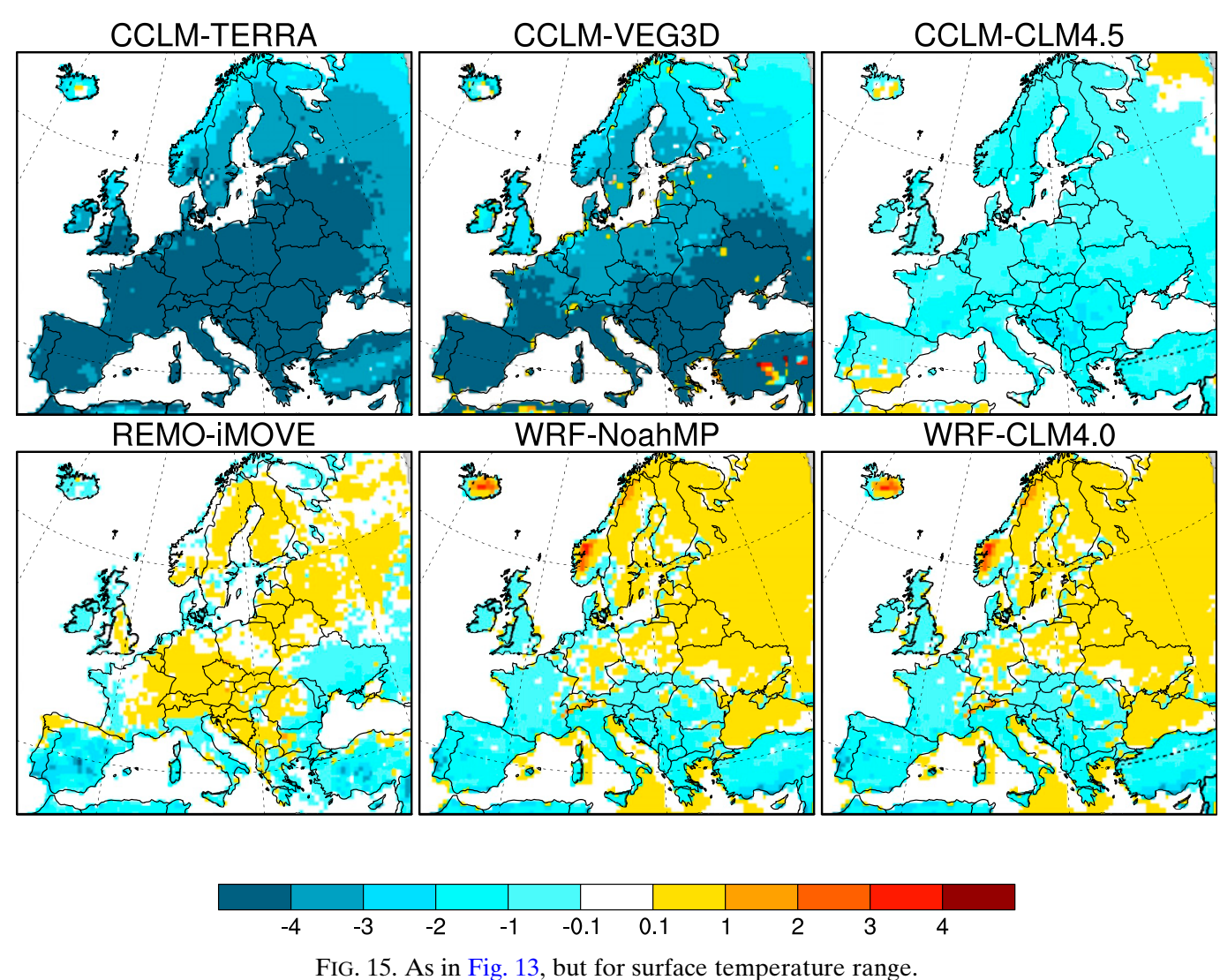

FIG. 15. As in Fig. 13, but for surface temperature range.

consequently in the diurnal temperature cycles, must be caused by the surface roughness, as already suggested by Lee et al. (2011) and Burakowski et al. (2018). At the same time, CCLMVEG3D FOREST_mod behaves much more like the CCLMVEG3D GRASS simulation than the CCLM-FOREST run. But compared to the CCLM-VEG3D GRASS simulation, completely different albedo and LAI values are used. Thus, the impact of these land use characteristics on the turbulent heat exchange is rather small. For the CCLM-VEG3D simulations, it can therefore be suggested that the impact of re/afforestation on the diurnal temperature cycles in Europe is to a large extent induced by the higher surface roughness of a forest and is not mainly driven by the albedo warming and evaporative cooling effects, as generally assumed (e.g., Bonan 2008; Swann et al. 2012). Since on the one hand comparable interrelations are simulated for each member of the LUCAS-Ensemble, and on the other hand, surface roughness values of the same magnitude are used in all RCMs (Table 1), it seems reasonable to conclude that changes in the diurnal temperature cycle are in all models primarily caused by the increased surface roughness with re/afforestation. But this assumption has to be verified in further model studies.

In general, the higher surface roughness of a forest increases the turbulent mixing and facilitates the heat exchange with the atmosphere (Lee et al. 2011; Schultz et al. 2017). The additional amount of absorbed energy, due to the lower albedo values of a forest can therefore be transformed into an increased sensible heat flux instead of an increased warming of the soil and the surface. That means that more heat can be transported into the atmosphere, even if the surface temperature and consequently also the temperature gradient to the atmosphere is lower than over grassland. Thus, re/afforestation can lead to a warming of the atmosphere without an additional heating of the surface.

Furthermore, the surface roughness affects also the course of the nocturnal temperatures at the surface and in the lowest atmospheric model level. In general, the surface is cooling out during the night, due to the outgoing longwave radiation. As soon as the surface gets colder than the atmosphere, the direction of the heat transport changes from an upward to a downward heat exchange. Because of the higher surface roughness of a forest, the heat transport under stable atmospheric conditions from the atmosphere to the surface is more effective than over grassland (Schultz et al. 2017). This impact of the surface roughness on the nocturnal heat exchange is demonstrated by the increased sensible heat fluxes in the FOREST simulations of all LUCAS-Ensemble members during nighttime (Figs. 8c, 9c, and 10c). Thus, the nocturnal cooling of the surface proceeds slower with re/afforestation, resulting in higher surface temperatures in a forest (Figs. 8f, 9f, and 10f). At the same time, more thermal energy is removed from the atmosphere in all LUCAS members, leading to lower atmospheric temperatures at night (Figs. $8 \mathrm{~g}, 9 \mathrm{~g}$, and $10 \mathrm{~g}$ ). This process chain was already hypothesized by Lee et al. (2011) to 
CCLM-TERRA

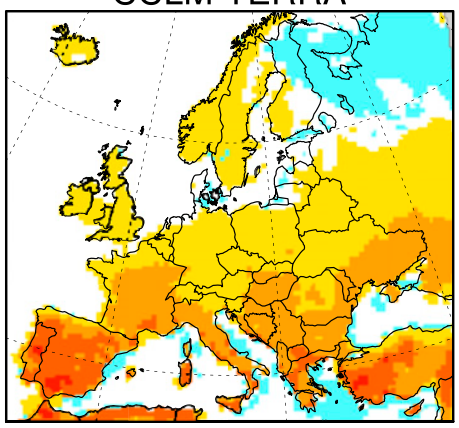

REMO-iMOVE

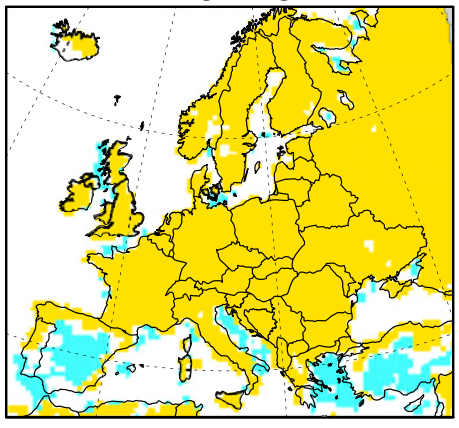

CCLM-VEG3D

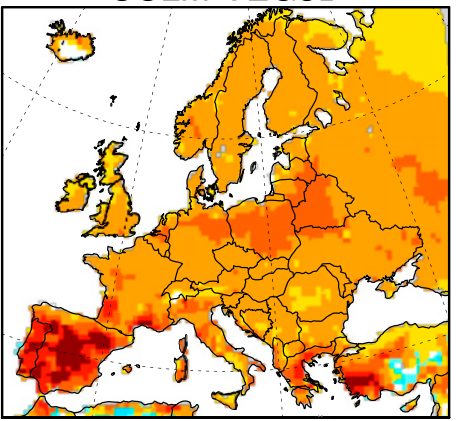

WRF-NoahMP

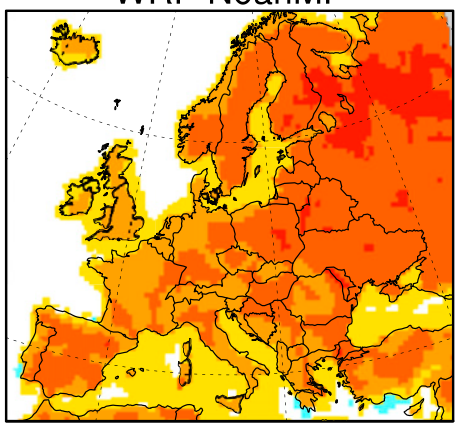

CCLM-CLM4.5

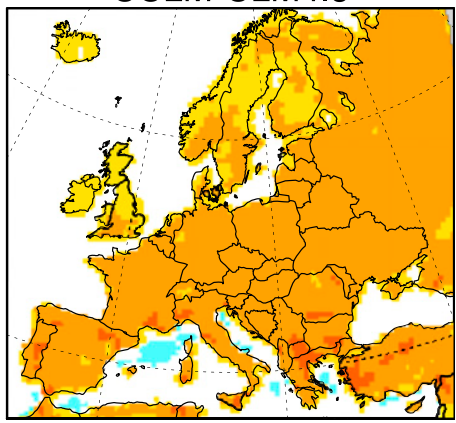

WRF-CLM4.0

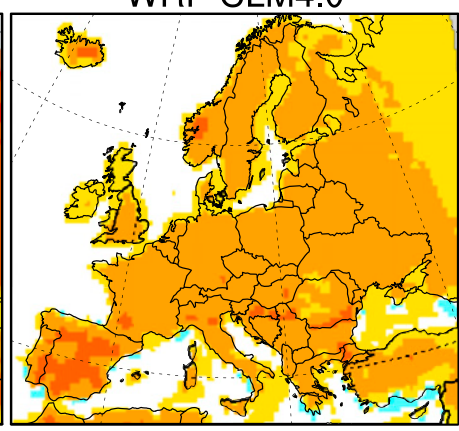

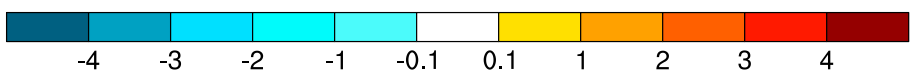

FIG. 16. As in Fig. 13, but for temperature range in the lowest atmospheric model level.

explain the observed increase in the diurnal temperature cycle at the surface with re/afforestation. But until now, such processes could not be reproduced in LUC model simulations (Lejeune et al. 2017; Davin et al. 2020). With the LUCAS simulations, now for the first time, these physical interrelationships could be identified within a model intercomparison study.

Nevertheless, an RCM ensemble study about the impact of regional re/afforestation on the surface temperatures has certain limitations. For instance, the effects of regional re/afforestation on the large-scale atmospheric circulation are not included in such a model approach. Induced changes in the atmospheric circulation by re/afforestation can create teleconnections (e.g., Swann et al. 2012), which can change the regional cloud cover (e.g., Laguë and Swann 2016) and thus, the radiative energy input and the regional surface temperatures (e.g., Laguë et al. 2019). Such feedbacks are therefore not considered in this study. To get a comprehensive understanding of the regional temperature response to re/afforestation, it is consequently essential that also in global model intercomparison studies, which account for these feedbacks, both $T_{\text {surf }}$ and $T_{\text {air }}$ are systematically analyzed.

\section{Conclusions}

In this study, the maximum theoretical impact of re/afforestation on the diurnal cycles of the temperature and the surface energy fluxes in the European summer was investigated. For this, the different components of the surface energy balance were analyzed in the LUCAS multimodel ensemble with respect to land use characteristics affecting the turbulent heat exchange. The main results of this study are as follows:

- Re/afforestation subdues the diurnal temperature cycle at the surface and amplifies the diurnal temperature cycle in the lowest atmospheric model level in summer. The results of a sensitivity study indicate that these opposing diurnal temperature cycles with re/afforestation in the midlatitudes are mainly caused by the higher surface roughness of a forest compared to grassland, enhancing the sum of the turbulent heat exchange between the surface and the atmosphere.

- Since the diurnal cycles at the surface and in the lowest atmospheric model level show opposing temperature responses to re/afforestation, the diagnostic calculation of the 2-m temperature does not reflect the occurring processes near the surface in summer and consequently misleading temperature responses can potentially be produced. Therefore, the sole use of the simulated 2-m temperature to assess the impact of LUC on the regional climate conditions in Europe is not recommended.

- Within the LUCAS-Ensemble, most of the models simulate colder surface temperatures during the day and a reduced cooling during the night with re/afforestation in summer. These results are in agreement to observation-based studies in the midlatitudes. Thus, for the first time the observed temperature response to re/afforestation could be reproduced within a model intercomparison study. Nevertheless, a model uncertainty exists for the surface temperature, since 
the processes of absorbing solar radiation and transforming it into turbulent heat fluxes are differently weighted in the RCMs. Thus, further model development is needed to improve the description of the relevant processes.

- Because of an increased surface roughness, re/afforestation generally enhances the sensible heat transport into the atmosphere. As a result, re/afforestation leads to a warming of the lowest atmospheric model level during the day in the midlatitudes in summer.

Acknowledgments. LUCAS is supported by WCRP CORDEX as a Flagship Pilot Study. Marcus Breil acknowledges funding by the Federal Ministry of Education and Research in Germany (BMBF) under the PalMod research program. Edouard L. Davin acknowledges support from the Swiss National Science Foundation (SNSF) through the CLIMPULSE project and from the Swiss National Supercomputing Centre (CSCS) for computing resources. The work of E. Katragkou and G. Sofiadis was supported by computational time granted from the Greek Research and 265 Technology Network (GRNET) in the National HPC facility ARIS under project ID pr005025_thin and the AUTH-IT scientific support center. Authors R. M. Cardoso and P. M. M. Soares acknowledge the projects LEADING (PTDC/CTA-MET/28914/ 2017) and FCT-UID/GEO/50019/2019-Instituto Dom Luiz. P. Hoffmann is funded by the Climate Service Center Germany (GERICS) of the Helmholtz-Zentrum Geesthacht in the frame of the HICSS (Helmholtz-Institut Climate Service Science) project LANDMATE. Author S. Strada has been supported by the TALENTS3 Fellowship Programme (FP code 1718349004) funded by the autonomous region Friuli Venezia Giuliavia the European Social Fund (Operative Regional Programme 2014-2020) and administered by the AREA Science Park (Padriciano, Italy). The data used in this study are available upon request from the corresponding author.

\section{REFERENCES}

Alkama, R., and A. Cescatti, 2016: Biophysical climate impacts of recent changes in global forest cover. Science, 351, 600-604, https://doi.org/10.1126/science.aac8083.

Bonan, G. B., 2008: Forests and climate change: Forcings, feedbacks, and the climate benefits of forests. Science, 320, 14441449, https://doi.org/10.1126/science.1155121.

Braun, F. J., and G. Schädler, 2005: Comparison of soil hydraulic parameterizations for mesoscale meteorological models. J. Appl. Meteor., 44, 1116-1132, https://doi.org/10.1175/JAM2259.1.

Breil, M., and G. Schädler, 2017: Quantification of the uncertainties in soil and vegetation parameterizations for regional climate simulations in Europe. J. Hydrometeor., 18, 15351548, https://doi.org/10.1175/JHM-D-16-0226.1.

—, H. J. Panitz, and G. Schädler, 2017: Impact of soilvegetation-atmosphere interactions on the spatial rainfall distribution in the central Sahel. Meteor. Z., 26, 379-389, https://doi.org/10.1127/metz/2017/0819.

Burakowski, E., A. Tawfik, A. Ouimette, L. Lepine, K. Novick, S. Ollinger, C. Zarzycki, and G. Bonan, 2018: The role of surface roughness, albedo, and Bowen ratio on ecosystem energy balance in the eastern United States. Agric. For. Meteor., 249, 367-376, https://doi.org/10.1016/j.agrformet. 2017.11.030.
Cherubini, F., N. Huang, X. Hu, M. H. Tölle, and A. H. Strømman, 2018: Quantifying the climate response to extreme land cover changes in Europe with a regional model. Environ. Res. Lett., 13, 074002, https://doi.org/10.1088/1748-9326/aac794.

Christensen, J. H., and O. B. Christensen, 2007: A summary of the PRUDENCE model projections of changes in European climate by the end of this century. Climatic Change, 81, 7-30, https://doi.org/10.1007/s10584-006-9210-7.

Davin, E. L., and N. de Noblet-Ducoudré, 2010: Climatic impact of global-scale deforestation: Radiative versus nonradiative processes. J. Climate, 23, 97-112, https://doi.org/10.1175/ 2009JCLI3102.1.

_ S. I. Seneviratne, P. Ciais, A. Olioso, and T. Wang, 2014: Preferential cooling of hot extremes from cropland albedo management. Proc. Natl. Acad. Sci. USA, 111, 9757-9761, https://doi.org/10.1073/pnas.1317323111.

_ in Europe: First results from the LUCAS (Land Use and Climate Across Scales) regional climate model intercomparison. Earth Syst. Dyn., 11, 183-200, https://doi.org/10.5194/esd11-183-2020.

Deardorff, J., 1978: Efficient prediction of ground surface temperature and moisture, with inclusion of a layer of vegetation. J. Geophys. Res., 83, 1889-1903, https://doi.org/10.1029/ JC083iC04p01889.

Dee, D. P., and Coauthors, 2011: The ERA-Interim reanalysis: Configuration and performance of the data assimilation system. Quart. J. Roy. Meteor. Soc., 137, 553-597, https://doi.org/ 10.1002/qj.828.

de Noblet-Ducoudré, N., and Coauthors, 2012: Determining robust impacts of land-use-induced land cover changes on surface climate over North America and Eurasia: Results from the first set of LUCID experiments. J. Climate, 25, 3261-3281, https://doi.org/10.1175/JCLI-D-11-00338.1.

Duveiller, G., J. Hooker, and A. Cescatti, 2018a: The mark of vegetation change on Earth's surface energy balance. Nat. Commun., 9, 679, https://doi.org/10.1038/s41467-017-02810-8.

— change: A process-based evaluation framework for confronting land surface models with satellite observations. Earth Syst. Sci. Data, 10, 1265-1279, https://doi.org/10.5194/essd-10-1265-2018.

Gálos, B., S. Hagemann, A. Hänsler, G. Kindermann, D. Rechid, K. Sieck, C. Teichmann, and D. Jacob, 2013: Case study for the assessment of the biogeophysical effects of a potential afforestation in Europe. Carbon Balance Manage., 8, 3, https:// doi.org/10.1186/1750-0680-8-3.

Jacob, D., and R. Podzun, 1997: Sensitivity studies with the regional climate model REMO. Meteor. Atmos. Phys., 63, 119129, https://doi.org/10.1007/BF01025368.

— , and Coauthors, 2012: Assessing the transferability of the regional climate model REMO to different COordinated Regional Climate Downscaling EXperiment (CORDEX) regions. Atmosphere, 3, 181-199, https://doi.org/10.3390/ atmos3010181.

— , and Coauthors, 2014: EURO-CORDEX: New high-resolution climate change projections for European impact research. Reg. Environ. Change, 14, 563-578, https://doi.org/10.1007/s10113013-0499-2.

Jia, G., and Coauthors, 2019: Land-climate interactions. Climate Change and Land: An IPCC Special Report on Climate Change, Desertification, Land Degradation, Sustainable Land Management, Food Security, and Greenhouse Gas Fluxes in Terrestrial Ecosystems, J. Skea et al., Eds., IPCC, 131-247. 
Kumar, S., P. A. Dirmeyer, V. Merwade, T. DelSole, J. M. Adams, and D. Niyogi, 2013: Land use/cover change impacts in CMIP5 climate simulations: A new methodology and 21st century challenges. J. Geophys. Res. Atmos., 118, 6337-6353, https:// doi.org/10.1002/JGRD.50463.

Laguë, M. M., and A. L. Swann, 2016: Progressive midlatitude afforestation: Impacts on clouds, global energy transport, and precipitation. J. Climate, 29, 5561-5573, https://doi.org/10.1175/ JCLI-D-15-0748.1.

— , G. B. Bonan, and A. L. Swann, 2019: Separating the impact of individual land surface properties on the terrestrial surface energy budget in both the coupled and uncoupled landatmosphere system. J. Climate, 32, 5725-5744, https://doi.org/ 10.1175/JCLI-D-18-0812.1.

Lawrence, P. J., and T. N. Chase, 2007: Representing a new MODIS consistent land surface in the Community Land Model (CLM 3.0). J. Geophys. Res., 112, G01023, https:// doi.org/10.1029/2006JG000168.

Lee, X., and Coauthors, 2011: Observed increase in local cooling effect of deforestation at higher latitudes. Nature, 479, 384387, https://doi.org/10.1038/nature10588.

Lejeune, Q., E. L. Davin, B. P. Guillod, and S. I. Seneviratne, 2015: Influence of Amazonian deforestation on the future evolution of regional surface fluxes, circulation, surface temperature and precipitation. Climate Dyn., 44, 2769-2786, https://doi.org/ 10.1007/s00382-014-2203-8.

_ - S. I. Seneviratne, and E. L. Davin, 2017: Historical land-cover change impacts on climate: Comparative assessment of LUCID and CMIP5 multimodel experiments. J. Climate, 30, 1439-1459, https://doi.org/10.1175/JCLI-D-16-0213.1.

—, E. L. Davin, L. Gudmundsson, J. Winckler, and S. I. Seneviratne, 2018: Historical deforestation locally increased the intensity of hot days in northern mid-latitudes. Nat. Climate Change, 8, 386-390, https://doi.org/10.1038/s41558-018-0131-z.

Li, Y., M. Zhao, S. Motesharrei, Q. Mu, E. Kalnay, and S. Li, 2015: Local cooling and warming effects of forests based on satellite observations. Nat. Commun., 6, 6603, https://doi.org/10.1038/ ncomms7603.

Meier, R., and Coauthors, 2018: Evaluating and improving the Community Land Model's sensitivity to land cover. Biogeosciences, 15, 4731-4757, https://doi.org/10.5194/bg-15-4731-2018.

Monin, A., and A. Obukhov, 1954: Basic laws of turbulent mixing in the surface layer of the atmosphere. Contrib. Geophys. Inst. Acad. Sci. USSR, 151, e187.

Naudts, K., Y. Chen, M. J. McGrath, J. Ryder, A. Valade, J. Otto, and S. Luyssaert, 2016: Europe's forest management did not mitigate climate warming. Science, 351, 597-600, https:// doi.org/10.1126/science.aad7270.

Niu, G. Y., and Coauthors, 2011: The community Noah land surface model with multiparameterization options (Noah-MP): 1. Model description and evaluation with local-scale measurements. J. Geophys. Res., 116, D12109, https://doi.org/10.1029/ 2010JD015139.

Oleson, K. W., and Coauthors, 2010: Technical description of version 4.0 of the Community Land Model (CLM). NCAR Tech. Note NCAR/TN-478+STR, 257 pp., https://doi.org/ 10.5065/D6FB50WZ.
- and Coauthors, 2013: Technical description of version 4.5 of the Community Land Model (CLM). NCAR Tech. Note NCAR/ TN-503+STR, 420 pp., https://doi.org/10.5065/D6RR1W7M.

Perugini, L., L. Caporaso, S. Marconi, A. Cescatti, B. Quesada, N. de Noblet-Ducoudré, J. I. House, and A. Arneth, 2017: Biophysical effects on temperature and precipitation due to land cover change. Environ. Res. Lett., 12, 053002, https:// doi.org/10.1088/1748-9326/aa6b3f.

Rechid, D., E. L. Davin, N. de Noblet-Ducoudré, and E. Katragkou, 2017: CORDEX Flagship Pilot Study "LUCAS-Land Use \& Climate Across Scales"-A new initiative on coordinated regional land use change and climate experiments for Europe. Proc. 19th EGU General Assembly, EGU2017, Vienna, Austria, European Geophysical Union, 13172.

Rockel, B., A. Will, and A. Hense, 2008: The regional climate model COSMO-CLM (CCLM). Meteor. Z., 17, 347-348, https://doi.org/10.1127/0941-2948/2008/0309.

Schädler, G., 1990: Numerische Simulationen zur Wechselwirkung zwischen Landoberfläche und atmosphärischer Grenzschicht. $\mathrm{Ph}$.D. dissertation, Institut für Meteorologie und Klimaforschung, Universität Karlsruhe, 217 pp.

Schrodin, E., and E. Heise, 2002: A new multi-layer soil model. COSMO Newsletter, No. 2, Consortium for Small-Scale Modeling, Offenbach, Germany, 149-151, http://www.cosmo-model.org/ content/model/documentation/newsLetters/newsLetter02/ newsLetter_02.pdf.

Schultz, N. M., P. J. Lawrence, and X. Lee, 2017: Global satellite data highlights the diurnal asymmetry of the surface temperature response to deforestation. J. Geophys. Res. Biogeosci., 122, 903-917, https://doi.org/10.1002/2016JG003653.

Schwaab, J., E. Davin, P. Bebi, A. Duguay-Tetzlaff, L. Waser, and R. Meier, 2020: Increasing the broad-leaved tree fraction in European forests mitigates hot temperature extremes. Sci. Rep., 10, 14153, https://doi.org/10.1038/s41598-020-71055-1.

Skamarock, W. C., and Coauthors, 2008: A description of the Advanced Research WRF version 3. NCAR Tech. Note NCAR/ TN-475+STR, 113 pp., https://doi.org/10.5065/D68S4MVH.

Swann, A. L., I. Y. Fung, and J. C. Chiang, 2012: Mid-latitude afforestation shifts general circulation and tropical precipitation. Proc. Natl. Acad. Sci. USA, 109, 712-716, https://doi.org/ 10.1073/pnas.1116706108.

Tang, B., X. Zhao, and W. Zhao, 2018: Local effects of forests on temperatures across Europe. Remote Sens., 10, 529, https:// doi.org/10.3390/rs10040529.

Tölle, M. H., M. Breil, K. Radtke, and H. J. Panitz, 2018: Sensitivity of European temperature to albedo parameterization in the regional climate model COSMO-CLM linked to extreme land use changes. Front. Environ. Sci., 6, 123, 10.3389/fenvs.2018.00123; Corrigendum, 7, 12, https://doi.org/10.3389/fenvs.2019.00012.

Wilhelm, C., D. Rechid, and D. Jacob, 2014: Interactive coupling of regional atmosphere with biosphere in the new generation regional climate system model REMO-iMOVE. Geosci. Model Dev., 7, 1093-1114, https://doi.org/10.5194/gmd-71093-2014.

Winckler, J., and Coauthors, 2019: Different response of surface temperature and air temperature to deforestation in climate models. Earth Syst. Dyn., 10, 473-484, https://doi.org/10.5194/ esd-10-473-2019. 